\title{
Harnessing Untapped Hydropower
}

This chapter has its foundation in papers given at the IEEE PES Summer Meeting, Vancouver, British Columbia in 2001. Since that conference, the world has embraced more strongly a new awareness of the challenge of global warming. In reviewing the opportunities to address the problem of climate change, hydroelectric power generation may be seen in a more positive light compared to other alternative power generation technologies, not withstanding the responsible attention that the hydro industry must continue pay to the environmental and social consequences of the construction and operation of a major hydroelectric project.

In the light of the ongoing review of economic development and the dominant role that electricity generation takes in such progress, this chapter seeks to review the opportunities for hydropower development in selected countries/locations worldwide. The authors are well aware that no single volume or chapter can fully catalogue the potential, but this is an attempt to record some of the aspects of the technology that influence the opportunities for development and some examples from the more promising markets.

There are a number of unique benefits from hydropower, rarely found in other sources of energy. Debates continue on the emissions from reservoirs, but on balance, few would now argue that the environmental benefits of hydropower are less than fossil-fuel power generation. The calculated savings of Greenhouse Gases (GHG) in 1997 by the operation of hydropower were equivalent to all the automobiles on the planet (in terms of avoided fossil fuel generation).

Development of all the remaining hydroelectric potential could not hope to satisfy total future world demand for electricity, but implementation of even half of this potential could have enormous environmental benefits in terms of avoided generation of GHG by fossil fuels.

With the mature technologies available to mankind, a combination of Nuclear power, hydropower and pumped storage could be the basis for addressing the issues of global warming.

\subsection{General}

Carefully planned hydropower development can make a vast contribution to improving living stands in the developing world (Asia, Africa, Latin America), where the greatest potential still exists. Approximately 2 billion people in rural areas of developing countries are still without an electricity supply. 
In the context of this chapter, large hydro is defined as a plant capacity between 10 megawatts (MW) and 18,000 MW, while small hydro is defined as a plant capacity between 1 and $10 \mathrm{MW}$. While focusing on large hydro, it is acknowledged that, in the recent past, much emphasis has been put on the environmental integration of small hydro plants into river systems in order to minimize environmental impacts, incorporating new technology and operating methods.

As the most mature and important of the clean, renewable energy options, hydropower is often one of a number of benefits of a multipurpose water resources development project. As hydro schemes are generally integrated within multipurpose development schemes, they can often help to subsidize other vital functions of a project. Typically, a dam and its associated reservoir results in a number of secondary benefits associated with human wellbeing, such as secure water supply, irrigation for food production and flood control, and societal benefits such as increased recreational opportunities, improved navigation, the development of fisheries, cottage industries, etc. This is not the case for any other source of energy.

As indicated, existing hydropower represents a significant potential contributor to world energy resources. In 2007 renewables (excluding large hydro) accounted for 3.4\% of world energy generation, while large hydro accounted for $15 \%$ [1]. This reference indicates that this was

“... down from 19 percent a decade ago. Large hydro grew during the five-year period 2002-2006 at a global average of 3 percent per year (less than 1 percent in developed countries). China has seen the highest growth, at over 8 percent per year during the period."

At the commencement of the period reviewed (2002) $44 \%$ of the world's hydropower was generated in four countries. The largest generators were Canada with $315 \mathrm{GWh}$ and China with 309 GWh, followed closely by Brazil with $282 \mathrm{GWh}^{[2]}$ and the United States with 255 GWh. By continents, Asia accounted for $24 \%$ of the world's hydro generation, with 618 GWh, followed by North America with $23 \%$ or 595 GWh and Europe with $20 \%$ or 537 GWh.

At the end of the period studied;

"The top five hydropower producers [in 2006] were China (14 percent of world production), Canada and Brazil (12 percent each), the United States (10 percent), and Russia (6 percent). China's hydro growth has kept pace with its rapidly growing power sector, with about 6 Gigawatt (GW) of large hydro and 6 GW of small hydro added in 2006. Many other developing countries continue to actively develop hydro".

Asia is constructing more and more hydropower capacity as its economies mushroom and although Canadian hydro generation is also growing, China has already overtaken Canada, to become the largest hydro generator in the world [3]. Russia lies in fifth place with 180 GWh and Norway is sixth with 125 GWh. Norway is regarded by many as having the best managed hydro system in the world, which accounts for $99.3 \%$ of the total power generated in that country. 
An additional US \$15-20 billion continues to be invested annually in large hydropower. 12 to $14 \mathrm{GW}$ was added in 2006 for a world total of $770 \mathrm{GW}$ added in 2006.

The contribution of hydro reflected by the above numbers are however difficult to monitor because of the lack of a central register.

Notwithstanding the reliance on hydropower by the northern European countries, overall, on a regional basis, hydroelectricity contributes the highest proportion to total electricity supply in Central and South America where it accounts for $68 \%$ of electricity produced.

Hydropower provided at the beginning of the new Millennium 20\% (2600 TWh/year) of the electricity world consumption (12900 TWh/year). It plays a major role in many countries. Of 175 countries, which have available data, more than 150 have hydropower resources. For 65 of them, hydro produces more than $50 \%$ of electricity; for 24 , more than $90 \%$ and for 10 , practically the total.

According to the Hydropower \& Dams Atlas [4], untapped world hydro potential is as follow:

- Gross hydro potential: $\quad 40,500 \mathrm{TWh} /$ year

- Technically feasible: $14,300 \mathrm{TWh} /$ year

- Economically feasible: $8,100 \mathrm{TWh} /$ year

The remaining exploitable capacity represents $1500 \mathrm{GW}$ (producing $5500 \mathrm{TWh} /$ year). It is estimated that by the middle of this century, the consumption of electricity in the world will be multiplied by a factor of 2.5 to 3.0. For the power generation sector, large hydropower remains an available energy technology and will contribute largely to this development, although environmental constraints, resettlement impacts, and the availability of sites have limited further growth in many countries. Particularly attractive hydropower sites i.e. high capacity factor sites are often used to directly supply high demand heavy industries such as smelters.

It is possible to harmonize the implementation of hydro plants with conservation of the environment and to ensure that the plants represent a net benefit to those affected by their construction.

The main advantages of hydroelectricity can be summarized briefly as follows:

- It is a reliable and mature technology, proven by one century of construction and operation.

- It is easily accessible, particularly for developing countries.

- It plays a major role in reducing greenhouse gas emissions in terms of avoided generation by fossil fuels.

- The fact that unit speeds are slow, and other design factors, contribute to a very low operation and maintenance costs. 
- It is competitive and the $\mathrm{kWh}$ cost (once completed) does not depend on variations in combustible costs and on international economic politics.

- It is an important factor in supporting energy and economic independence for a country, because of the effective zero fuel costs and absence of reliability on foreign fuel sources.

Finally, hydropower stations are very often integrated within multipurpose schemes, which satisfy other fundamental human needs (irrigation, domestic and industrial water supply, flood protection) and hydropower can help finance these other functions.

A drawbacks of large hydro development is the generally longer construction lead time, higher construction cost compared to combustion turbines and some other fossil fuel plants, although in some countries coal and oil plants (and of course nuclear plants) also have long lead times. The long lead times with the correspondingly long "payback" is a severe constraint to utilization of non-government funding.

The impact of higher construction cost is more than offset by zero fuel cost and hence, hydro power plants generally yield higher operating margins. Overall returns should better match those of thermal plants.

\subsection{System Benefits}

The overriding challenge of global warming will likely factor heavily into system planning throughout the developed and developing world, and indications are that hydro power will have a strong part to play in the various system portfolios.

Almost all power generation technologies already developed, and those under development suffer from one or both of the following constraints that do not affect hydropower - lack of flexible response without significant effects on efficiency, or lack of sustainability because of the energy source. The efficiency penalties associated with ramping up output apply to the (generally) polluting technologies that need to be maintained at the highest efficiencies to lower their carbon imprint (such as coal fired generation) while the relative unpredictability of wind power and solar power and the intermittent (while predictable) nature of tidal power - three of the promising new technologies - necessitates some form of energy storage.

For all the above technologies, as well as nuclear generation - which may turn out to be the only way to maintain the required level of energy generation to maintain current standards of living in the developed world and to increase standards to an acceptable level in the developing world - the benefits of the flexibility of hydropower and the storage potential are, at present irreplaceable.

The degree to which hydropower contributes to the system stability and response will depend on the economic growth - and the change in standard of living - in each country. As countries develop, three drivers (among many) affect their requirements for system flexibility; the mix of heavy industry that the economy embraces; the speed at which constant (residential) heavy 
power users such as refrigerators and air conditioning are installed; and the adoption at different times of technology with intermittent heavy power demands such as recharging of battery operated cars. The relative lack of flexibility of some of the other power sources ensures that hydropower stations, either river based or off-stream pumped storage seems certain to continue to be vital in system operation. The only counter trend to this driver would seem to be the interconnection of systems - either through land connections or undersea HVDC transmission, which also must continue and accelerate.

Hydropower provides vital benefits to an electrical system. When water is stored in large quantities in the reservoir behind a dam, or has been pumped up to the upper reservoir of a pumped storage scheme, it is immediately available for use when required. Pumped storage technology has been developed sufficiently to minimize the losses in storage, which principally arise because of the hydraulic losses in the conduit system. The difference between the "value" of the energy during the pumping cycle and the "value" during the generating cycle are usually large enough to overcome the efficiency penalties, making the technology ideal for smoothing the output of a large base load plant such as a nuclear station. Thus the benefits of hydro extend beyond simple generation.

The first and most obvious benefit is the flexibility of a large hydro power station to provide large amounts of power within a minute or so of demand (sometimes seconds depending on how the plant is configured and operated). This flexibility and the flexibility of ramping, allow the hydro plant to respond to the demand curve, and to efficiently "lop the peaks" of demand allowing other fossil plants to operate at their constant efficient output. Pumped storage can of course act on the obverse of this problem by converting excess power from the fossil plants to stored energy.

The second benefit is truly a family of benefits, known as secondary benefits. These secondary benefits include:

- Spinning reserve - the hydropower plant can operate at a zero load (and of course zero fuel consumption) while synchronized to the electric system. When loads increase, additional power can be loaded rapidly into the system to meet demand.

- Non-spinning reserve - Hydropower has a "quick start" time measured in seconds or minutes, compared with as much as 30 minutes for other turbines and hours for steam generation.

- Voltage support - Hydro is very useful in providing reactive power, thereby assuring that power will flow from generation to load.

- Regulation and frequency response - the ability to support the system during moment-to-moment fluctuations in system power requirements is met by a hydropower' plant's fast response characteristic making the technology especially desired to provide regulation and frequency response in a system with sensitive equipments.

- Black start capability - most hydro power plants have the ability to start generation without an outside source of power enabling the system to be brought up during catastrophes and providing auxiliary power to more complex generation sources that could take hours or even days to start. 


\subsection{Situation at Present}

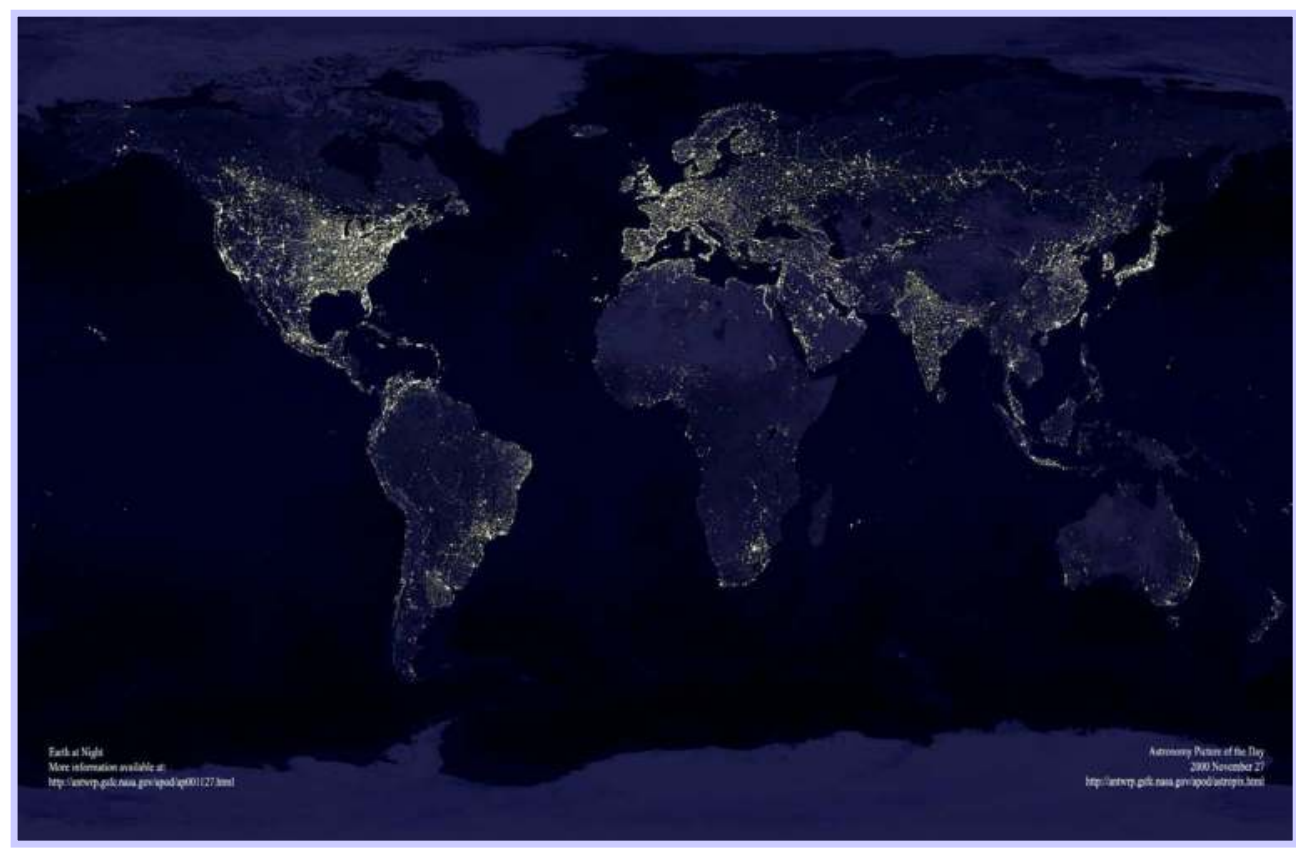

Fig. 2.1 Earth at Night

In reviewing the world energy demand, it is useful to examine Figure 2.1 showing the world from space at night. It can immediately be seen that almost the whole of Africa, most of the South American continent and large parts of China are without lights. This immediately underscores the main long-term markets for the utilizing of untapped hydro.

Hydropower is not the largest available renewable primary source. This mantle is held by biomass, but hydropower is the largest renewable source of electricity generation. Hydropower accounts for $6 \%$ of primary energy supply and $17 \%$ of electricity generation.

Although there are hydroelectric projects under construction in many countries, most of the remaining hydro potential may be found in the developing countries particularly in South and Central Asia, Latin America, and Africa. Other countries with significant remaining hydropower potential are Canada, Turkey and Russia.

Hydropower constitutes about $20 \%$ of the world's electricity generating capacity. The theoretical potential of worldwide hydropower is $2,800 \mathrm{GW}$, about four times greater than that which has been exploited.

However, the actual amount of electricity that will ever be generated by hydropower will be much lower than the theoretical potential, because of the environmental concerns and economic constraints. 
A study by the Utility Data Institute, USA, predicts that a world total of $695 \mathrm{GW}$ of new electricity capacity will come on line in the next ten years from all sources, 22 per cent of which will be hydro, 26 per cent gas, and 27 per cent coal, with the remainder coming from a variety of sources.

The world's total technical feasible hydro potential is estimated at about $14300 \mathrm{TWh} /$ year, of which about $8080 \mathrm{TWh} /$ year is currently considered economically feasible for development. About $723 \mathrm{GW}$ (or about $2600 \mathrm{TWh} /$ year) is already in operation, with a further $108 \mathrm{GW}$ under construction (Table 2.1) [4].

\begin{tabular}{|c|c|c|}
\hline Area & Technically feasible & $\begin{array}{l}\text { In operation \& under } \\
\text { construction }\end{array}$ \\
\hline Asia & $4,225,479$ & 699,636 \\
\hline China & $1,923,304$ & 198,700 \\
\hline Lao & 210,000 & 3,037 \\
\hline Myanmar & 160,000 & 1,450 \\
\hline Japan & 129,840 & 91,654 \\
\hline Cambodia & 83,000 & 0 \\
\hline CIS \& Russia & $2,105,600$ & 323,760 \\
\hline North America & $1,007,713$ & 601,791 \\
\hline South \& Central America & $3,933,770$ & 550,658 \\
\hline Peru & $1,091,540$ & 12,615 \\
\hline Europe & $1,158,029$ & 486,819 \\
\hline Africa & $1,590,828$ & 64,043 \\
\hline Oceania & 206,366 & 42,637 \\
\hline World total & $14,227,785$ & $2,769,344$ \\
\hline
\end{tabular}

Table 2.1 Hydropower Potential (GWh/year) ${ }^{[5]}$ 
The majority of the remaining hydro potential is found in developing countries in the regions mentioned, South and Central Asia, Latin America and Africa. In most of the European countries the economically feasible hydropower potential has mostly been harnessed.

A number of countries, such as China India, Iran and Turkey, are currently undertaking large-scale hydro development programs, and there are projects under construction in about 80 countries. According to the recent world surveys, a number of countries see hydropower as the key to their future economic development. Examples include Sudan, Rwanda, Mali, Benin, Ghana, Liberia, Guinea, Myanmar, Bhutan, Cambodia, Armenia, Kyrgyzstan, Cuba, Costa Rica, and Guyana.

In North America, hydropower is the most widely used form of renewable energy. The installed hydropower capacity amounts to 175 GW (67 GW in Canada, 99 GW in the US, and $10 \mathrm{GW}$ in Mexico).

Hydropower accounts for $57 \%$ of the electricity generated in Canada, $7 \%$ in the US (the US uses hydropower for peaking not base load) and $12 \%$ in Mexico. Canada's economical hydropower potential is second only to that of Brazil in the Western Hemisphere and still has several projects under either construction or planning, amounting to $6.6 \mathrm{GW}$.

Latin America has a very large hydropower potential. Many countries rely heavily on hydropower for their electricity supply. For instance, hydropower makes up $80 \%$ of Brazil's electricity generation.

Brazil has plentiful hydropower resources. Its installed hydropower capacity is already 64 GW. The capacity under construction or planning is more than $25 \mathrm{GW}$. One of the hydropower plants under construction is the giant $11.18 \mathrm{GW}$ Belo Monte power plant. Capacity under construction or planning in other South American countries, particularly Argentina, Bolivia, Chile, Colombia, Guyana, Peru, and Venezuela, amounts to 9.7 GW together with $4.4 \mathrm{GW}$ of hydropower capacity under construction or planning in Central American countries.

China has the largest hydropower resources in the world, with a host of rivers. Its installed hydropower capacity rested at $83 \mathrm{GW}$ at the end of 2002. A large number of hydropower plants are under construction or planning, amounting to $77.7 \mathrm{GW}$. The giant 18.2 GW Three Gorges Dam with a dam height of $181 \mathrm{~m}$ on the Yangtze River (the country's longest river) is the world's largest hydropower project so far.

Russia holds fifth place with 180 GWh and Norway in sixth with 125 GWh. Norway is regarded by many as having the best managed hydro system in the world, which accounts for $99.3 \%$ of the total power generated in that country.

\subsection{Prior Development Methods}

The approach for development of hydropower generation worldwide has progressed through three significant phases since the beginning of the 19th century. These phases have been observed in all regions of the world and correlate directly with the historical 
developmental phases (colonial, independent and multilateral etc), the type of projects selected for development, and the resources available for implementation.

In general, the phases can be described as follows:

Phase I can be thought of as the birth of modern power systems and comprises the time from the first development of the electric generation industry through to the major expansions required after the Second World War. This period was characterized by project development by largely private sector utilities, colonial development in discrete parts of territories and industrial companies seeking to meet immediate demands. Development was often managed or controlled by engineers due to the unique nature of the projects and the state of knowledge in the industry. Financing was limited and projects were developed as needed, often for specific industrial projects in the developing world or for the limited demand from colonial outposts. The configuration and capacity of the projects considered was driven by economic and technical factors usually leading to modest scale projects that could be financed from the resources of the relatively small utilities in existence at that time. The developed world was creating interconnecting grids during this process but typically in the developing world, the grids remained isolated because of the limited colonial development objectives.

Phase II was ushered in by the rapid economic growth and industrialization following the Second World War as well as decolonization and independence. Energy use expanded significantly in this period as development accelerated in the already industrialized societies and spread internationally. The rate of growth envisaged and promoted by economic planners exceeded the capability of the nascent private utilities to finance the required generation expansion. Accordingly, many governments in the developed world started to take a direct role in the power sector through the formation and/or expansion of publicly owned utilities. Regulation of the power sector accompanied this transition as governments sought to control the price of retail energy. In the developing world, the major financing needs in this period were supported by the multilateral financing agencies such as the World Bank. During the 1960s and 1970s utilities embarked on a program of building much larger projects supported by government financing resources, in an effort to keep pace with development and in many cases to foster development in emerging economies. Many projects were configured to be very large. They were often multi purpose designed to meet several needs including water supply, flood control and irrigation as well as power generation, and were intended to be national development "engines" as well as for the simple purpose of generation. Unfortunately, many of the difficulties that have been assessed by the World Commission on Dams in the selected review projects relate to these mega projects.

In the most recent Phase III that has evolved in the last ten to fifteen years, the world has in many ways returned to the development model used during the emerging years of the power industry. This can be characterized the world over by the privatization of power generation and distribution systems and the 
implementation of "private" projects driven by investors as well as a retreat by multinationals from direct funding of large hydropower. One of the most important elements driving this transition is the realization that foreign direct investment under appropriate conditions can be an important source of financing the large capital requirements of power sector expansion. In many ways, this reflects on the success of the efforts described here as "Phase II". Multi-lateral financing has ensured that many nations have matured politically and commercially so that largescale foreign private investment has becoming more viable. This current phase has several variants and the extent to which each country has moved down the road of market driven investment governs investment strategy adopted by private power developers. Today energy sales from independent power projects use various vehicles ranging from direct power purchase agreements with a utility at the outset of privatization to a sophisticated power pool or merchant market in the more developed markets. Though investment in power generation and in distribution has been significantly influenced by privatization, the creation of large-scale transmission interconnection has not attracted the market funds necessary for realization.

It is also conceivable that the private capital market may not be able to supply capital at the rate needed to address the issues of global warming.

The three phases of development orientation and philosophy presented above and reflected in the activity in the regions is of course a generalization and, perhaps, an oversimplification of the complex circumstances of national and international economic development. However, there is no question that during this period there has been a relatively linear chronological progress. This movement from initial limited and focused utility investment - through focus on major "economy-stimulating" projects - and, currently, back to a more market-driven investment profile is evident throughout most of the developing nations in the world and most certainly in Asia. An indication of the extent of dam building (which approximates to hydropower development) during these phases can be gained from Figure 2.2.

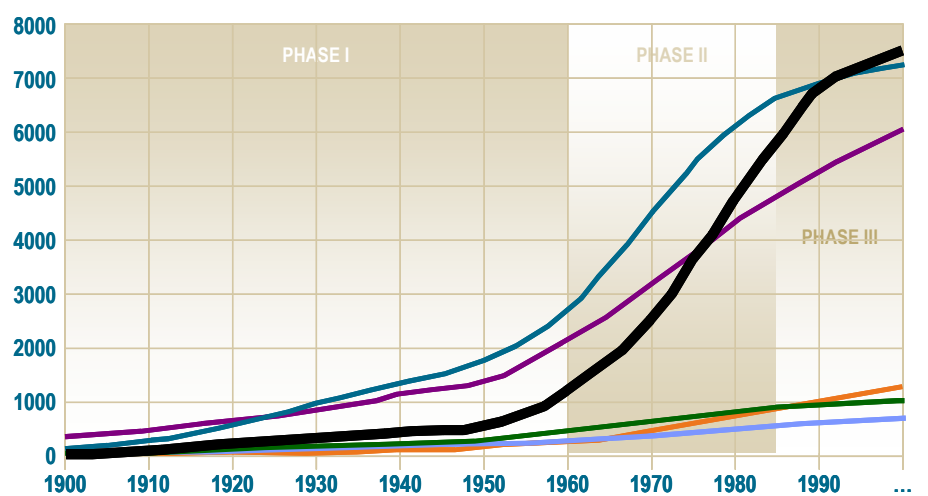

(Source: ICOLD, 1998. Excludes the time-trend of dams in China)
Asia

North America

Europe

Africa

South America

Australasia

Fig. 2.2. Extent of Dam Building Worldwide (1900 2000)[6] 
The urgent challenges of global climate change, and the general acceptance that energy generation must relay less on fossil fuels in the future, together with the realization that economic development is a forceful factor in the stabilization of the political world now necessitates a reconsideration of hydro development and consideration of the benefits of the sort of larger projects that cannot be funded by private financing, including large scale transmission interconnection.

\subsection{Review of Selected Regional Prospects}

Hydro is a mature technology, and has been developed all around the world. Resources are being developed at a rate of approximately $2.5 \%$ per annum, and the USA has achieved the greatest development of its resources with a total installed hydro capacity of 73,500 MW.

The World Energy Council estimated that in 1990 world energy demand was approximately $12,000 \mathrm{TWh}$, and postulates that in 2020 it will be nearly double at 23,000 TWh.

In 1990, hydro contributed 2,240 TWh of energy, representing $18.5 \%$ of the total, and if $50 \%$ of the total economically feasible resources were developed, in 2020, hydro would contribute approximately $28 \%$ of energy generation worldwide.

Table 2.2 indicates world hydro potential (in TWh) of each region:

\begin{tabular}{|l|l|l|l|}
\hline & Gross & Economic & Feasible \\
\hline Europe & 5,584 & 2,070 & 1,655 \\
\hline Asia & 13,399 & 3,830 & 3,065 \\
\hline Africa & 3,634 & 2,500 & 2,000 \\
\hline America & 11,022 & 4,500 & 3,600 \\
\hline Oceania & 592 & 200 & 160 \\
\hline Total & $\mathbf{3 4 , 2 3 1}$ & $\mathbf{1 3 , 1 0 0}$ & $\mathbf{1 0 , 4 8 0}$ \\
\hline
\end{tabular}

Table 2.2. World Hydro Potential by Region

Hydropower development in the regions reflects, as expected, economic development achieved by each region. The total hydro developed as of 1997 as a proportion of the economic hydro potential is shown in Table 2.3.

\begin{tabular}{|l|l|}
\hline Africa & $6 \%$ \\
\hline $\begin{array}{l}\text { South and Central } \\
\text { America }\end{array}$ & $18 \%$ \\
\hline Asia & $18 \%$ \\
\hline Oceania & $22 \%$ \\
\hline North America & $55 \%$ \\
\hline Europe & $65 \%$ \\
\hline
\end{tabular}

Table 2.3. Proportion of Hydro Developed, by Region 
There are commercially available sector reports noting in detail the various projects that have been identified region-by-region and nation-by-nation. These commercial reports are recommended for those developers seeking the viable opportunities particularly in the prospective markets in Africa, Asia and Central and South America. It is not the scope of this chapter to repeat the sector reports but merely to address some of the interesting aspects of development in particular regions.

The following sections provide an overview of recent and upcoming possibilities in a few markets.

\subsection{Canada}

About half of the Canadian provinces are responsible for the majority of hydroelectric energy production in Canada, with Quebec being a market leader. $60 \%$ of the countries electricity is supplied by hydropower and the total installed capacity is approximately 72,000 MW. The largest producers are provincially-owned electric utilities such as:

- Hydro-Quebec

- BC Hydro

- Manitoba Hydro

- Ontario Power Generation

- Newfoundland and Labrador Hydro.

These utilities have already developed a series of large-scale hydro sites across the country. One of the most significant hydroelectric developments in the world is La Grande complex on the Quebec side of James Bay. It has a capacity of over 15,000 MW. Some of the other large-scale hydro sites in Canada include:

- Churchill Falls station in Labrador

- Manicouagan-Outardes complex on the Quebec North Shore

- Sir Adam Beck station on the Niagara River in Ontario

- Nelson River development in Manitoba

- Gordon Shrum station in Northern British Columbia

- Columbia River complex in the southern part of British Columbia.

Electric utilities are the main generators of hydroelectric energy, however there are other electrical producers of hydroelectric energy. Several industrial companies own and operate hydroelectric facilities for their own use.

Canada's remaining (economic and environmentally acceptable) potential is spread throughout the country but is predominantly in the provinces of Alberta (12,000 MW), and Quebec and the Maritimes (25,000 MW). The others have approximate potential for about 4 to $5000 \mathrm{MW}$ each. 
Major projects are under construction in Quebec:

and Ontario:

- $\quad$ Eastmain $1 \quad-480 \mathrm{MW}$

- Chûte-Allard/RDC - $138 \mathrm{MW}$

- Péribonka - $385 \mathrm{MW}$

- Niagara Tunnel - C\$600 M

Near term projects in Québec \& Manitoba include:

- $\quad$ Eastmain 1A - $888 \mathrm{MW}$

- Wuskwatim - $200 \mathrm{MW}$

Planned Projects include:

- Québec

- La Romaine - 1550 MW

- Manitoba

- Keeyask - $620 \mathrm{MW}$

- Conawapa - $1250 \mathrm{MW}$

- Newfoundland \& Labrador

- $\quad$ Lower Churchill (Gull Island) -- 2000 MW

- Lower Churchill (Muskrat Falls) -- 824 MW.

For the purposes of this chapter, we examine three projects in planning by Manitoba Hydro.

Potential projects considered include three smaller or mid range hydro plants at Gull Rapids on the Nelson River, Notigi on the Rat River and Wuskwatim on the Burntwood River.

The three hydro options considered are all low impact projects with potential of $600 \mathrm{MW}$ at Gull and 1300 MW at Conawapa (and possibly 1900 MW more) on Nelson River. Notigi potential is $100 \mathrm{MW}$ and $200 \mathrm{MW}$ at Wuskwatim. There is possibly $650 \mathrm{MW}$ more on Burntwood River. Other potential from partially developable hydro sites in the province amounts to about $4000 \mathrm{MW}$.

Wuskwatim and Gull can be constructed to minimize their environmental impacts. Flooding would be less than 1-km square at Wuskwatim, Gull would be in the order of 48-km square, and Notigi Plant would have no additional flooding as the water control structure already exits. 
Methyl mercury production due to flooding would be minimal and Green House Gas (GHG) emissions would essentially be zero.

Construction cost including the transmission cost would be in the order of $\$ 500$ million for Notigi, \$1,000 million for Wuskwatim, and \$3,000 million for Gull. By comparison additional combustion turbines with a generation capability of 140-280 MW would cost about \$100 -\$200 million. The larger hydroelectric plant at Conawapa would cost about $\$ 5,000$ million including transmission to the load centers in the south.

Historic variability of water supply in the Nelson and Churchill Rivers Drainage basin over the last 80 to 100 years shows a range of percent average flow from a low of $55 \%$ to a high of $160 \%$. Manitoba Hydro's long term planning criteria must consider the lowest historical level for power resource planning, but plant structures including the spillways must be designed for maximum flood conditions.

Figure 2.3 shows the Manitoba Hydro hydraulic system with respect to the elevation levels along with the existing plant locations indicated. Figure 2.4 shows an illustrative view of Burntwood and Nelson Rivers areas in reference to potential new generation.

Transmission is a major consideration. Drivers for Manitoba Hydro include strong growth in its export sales, while provincial requirements are growing steadily. Export revenues grew almost 50 percent in the four years from 1996 to 2000 from \$250 million to \$376 million. Regulatory changes in the U.S. market, coupled with a burgeoning economy and a lack of new generation and transmission in the U.S. have meant steadily increasing prices for wholesale electricity exported to the U.S. from Canada.

Manitoba Hydro was been able to benefit from these changes, and now has the ability to market to approximately 35 export customers, compared to seven export customers in 1996. With domestic electricity consumption in Manitoba growing slowly but steadily, this means that over time the utility will have less and less available energy to sell on the export market. If it wants to maintain its current level of export sales, it will have to build new sources of generation.

Strong export sales have been a key reason that electricity rates in Manitoba have not risen as strongly as they might (for industrial customers, the rates remained stable for nearly ten years).

Manitoba Hydro has the capability of a number of east - west interconnection schemes which have been studied in the past such as the Manitoba - Ontario connection that included new generation in northern Manitoba with a north - south HVDC line. This project had an estimated cost of \$2 B.

Another east - west scheme that is viable is a $500 \mathrm{kV}$ HVDC multi terminal concept that covered Manitoba, Saskatchewan and Alberta Provinces, also known as western grid.

There has also been a number of north - south interconnection studies in the past to the States of Minnesota, North Dakota, Nebraska and Wisconsin. One current project which has recently been completed is a $230 \mathrm{kV}$ connection between western Manitoba and central 
North Dakota with a transmission line length of $200 \mathrm{~km}$ (and a cost of $\$ 55$ million). This project will re-establish Manitoba Hydro's import capability to $500 \mathrm{MW}$; it will also increase the import and export capabilities by $200 \mathrm{MW}$.

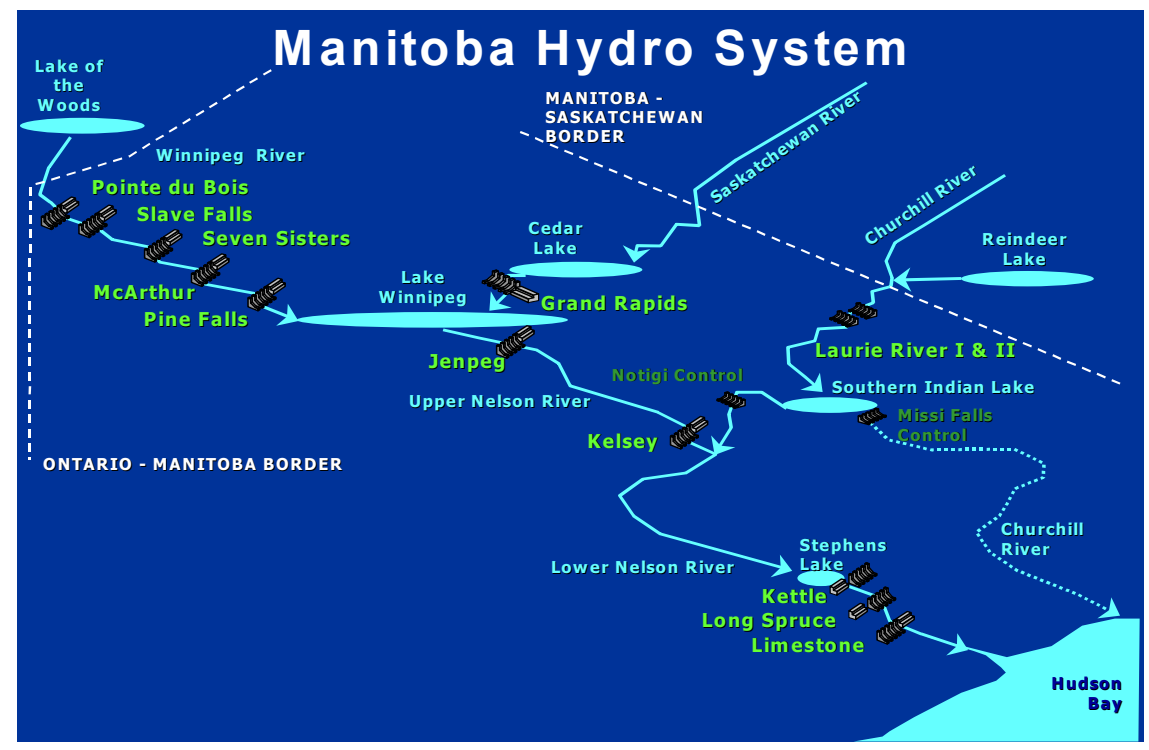

Fig. 2.3. Manitoba Hydro System

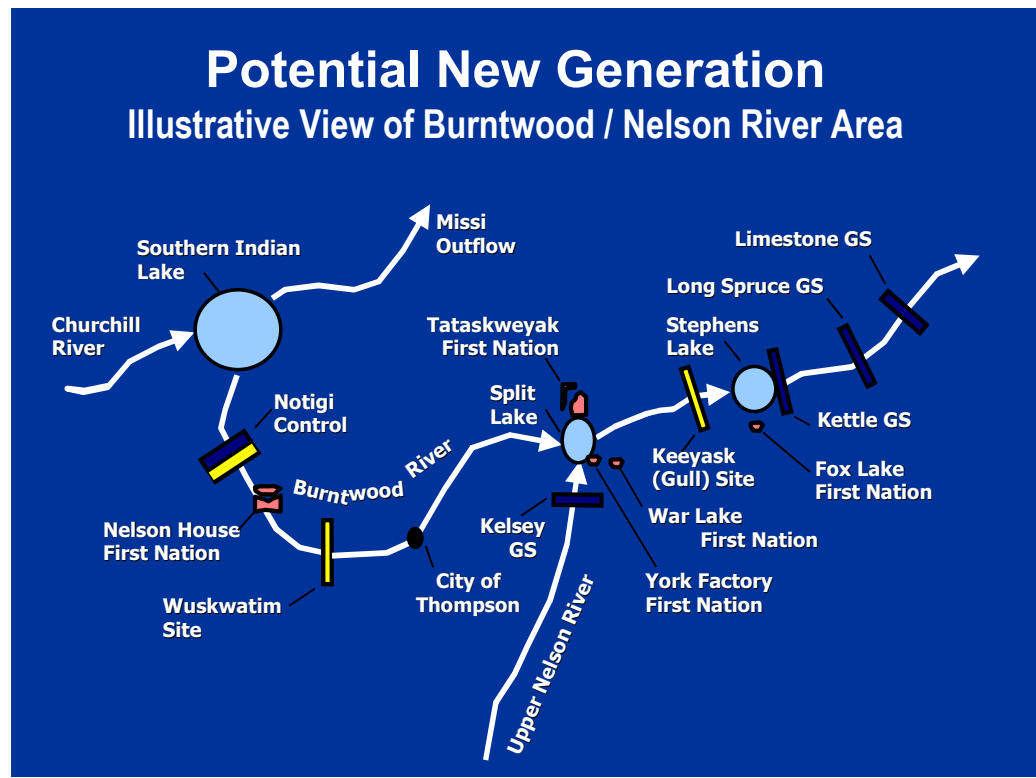

Fig. 2.4. Potential New Generation- Burntwood/Nelson River Area 


\subsection{South and South East Asia}

South and South East Asia, encompasses the SE Asian Tigers - with strong development and industrialization that will continue to ensure a strong power market - together with the Indian subcontinent and its peripheral countries, which are also poised to contribute to India's power. Notable potential exists (2005/2006 figures) as follows:

\subsubsection{Bhutan}

Development in Bhutan has resulted in an installed capacity of $445 \mathrm{MW}$, with a further 1,020 MW under construction. The capacity in planning - which varies from report to report is between $1660 \mathrm{MW}$ and 7,805 MW. Notable projects in planning include Bunakha (180 MW) \& Wang Chu (900 MW), both in the Wang Chu River valley. A further potential project Sankosh (of installed capacity 4,060 MW) has been identified.

\subsubsection{India}

India's economy is developing fast - with the consequent necessity for generation - and the country is endowed with economically exploitable and viable hydro potential assessed to be about 148,700 MW installed capacity. The major enterprise charged with developing it is National Hydropower Corporation but the National Thermal Power Corporation is developing Kol Dam and power plant and there are private power companies in the sector. As of 2005, the installed capacity in India is 31,982 MW with an additional 13,245 MW under construction. The largest projects under construction are Subansari lower (2,000 MW) Parbati (800 MW), and Omkareshwar (520 MW). 8,860 MW are planned approximating to 17 schemes.

\subsubsection{Laos}

Laos is developing hydro in order to provide power to the Thai and perhaps Vietnam grids. There are various private power companies developing sites and there are some substantial projects in construction and in the later stage of development. In 2005 the installed capacity was $673 \mathrm{MW}$ with a further 2,011 MW under construction. Between 3,000 and 5,000 MW are planned.

\subsubsection{Malaysia}

The installed capacity in 2005 was 2,078 MW. Most of the hydro potential of peninsular Malaysia has been developed and the potential now remains in Sarawak and Sabah. Although Ulu Terengganu is proceeding on the peninsular, the massive Bakun project which has an installed capacity of 2,400 MW - is the prime project under construction. Bakun has been under development for many years, and at various times an HVDC cable to peninsular Malaysia has been proposed. It appears that this cable may be implemented in the near future, most notably because existing gas supplies supporting combustion turbines are being depleted, rendering hydropower from Sarawak a desirable energy option. A new Sarawak Corridor of Renewable Energy ("SCORE") has been announced including Murum (900 MW), Limbang (150 MW), Barang (1,000 MW), and Baleh (1,000 MW) all planned for development in the near to medium future. 


\subsubsection{Myanmar}

The installed capacity in Myanmar is $745 \mathrm{MW}$, with an additional $1780 \mathrm{MW}$ under construction. The Myanmar Electric Power Enterprise has identified the potential for nearly 40,000 MW but capacity additions that are in planning, though unlikely to be realized in the foreseeable future are limited to approximately 8,000 MW.

\subsubsection{Nepal}

Nepal has very limited installed capacity, some 560 MW in 2005, with 69 MW under construction. However, as a result of the Himalayan topography, the hydro potential is enormous - some 43,000 MW is postulated. Although the 2007 World Energy Survey records no planned hydro, a cursory examination of the project list from the Nepal Electricity Authority indicates many projects, including West Seti, Arun, Kali Gandaki Pansheswar and many other projects of $200 \mathrm{MW}$ plus. The limited financial capacity of Nepal is a brake on development.

\subsubsection{Pakistan}

Pakistan had in 2005 an installed capacity of some 6,499 MW, dominated by the installations at Tarbela and Mangla. The potential economical installed capacity has been identified as 41,722 of which $734 \mathrm{MW}$ is under construction and some 8,900 to $27,000 \mathrm{MW}$ are in various stages of planning. To date, large scale hydro has been dominated by the Indus basin treaty signed between India and Pakistan in 1960, but projects such as Neelum Jhelum (969 MW) which will commence design this year, Dasu (2,712 MW) Bunji (1,500 MW), Pattan (1,172), Thakot $(1,043 \mathrm{MW})$ and Kohala $(740 \mathrm{MW})$ are included in the 8,900 MW planning figure. Kalabagh dam was conceived in 1953 and remains feasible for 2,400 MW installed capacity increasing to 3,600 MW. However there remains significant social difficulty in implantation. Another large project, Bashar could have an installed capacity of 3,600 MW,

\subsubsection{Vietnam}

The potential in Vietnam is put at $300,000 \mathrm{GWh} / \mathrm{yr}$ with an economically feasible potential of about $80,000 \mathrm{GWh} / \mathrm{yr}$. Total installed capacity in Vietnam is approximately 4,198 MW, and some 20 plants totaling 7,768 MW are currently reported to be under construction. In planning are another 4,600 MW.

\subsection{Africa}

As noted only $4 \%$ of Africa's technically feasible hydroelectric power has been developed. This is symptomatic of the continents lack of economic growth. At present only $10 \%$ of Africans have access to electricity - with the lowest per capita consumption in the world (450 kWh, compared to the world average of 2,326 kWh) - and there is an uneven distribution of power supply.

The existing infrastructure is under strain. The bulk of the region's generating capacity and transmission network was built in the 1950s and 1960s, and continued under investment in maintenance and renewal has left, in many countries, a system creaking. Technical and nontechnical losses typically exceed $20 \%$. Power outages, brown outs, and power surges are 
commonplace, whilst load shedding in times of drought are routine. A prolonged drought in 1999/2000 led to severe power outages in Kenya and Ethiopia, for example, whilst silting up of dams has led to a steady decline in capacity and concerns about dam failure. It is estimated that some of Kenya's dams are up to $70 \%$ silted and Malawi's, up to $80 \%$.

Africa's power sector is dominated by South Africa in Southern Africa, Egypt and Morocco in North Africa, and Nigeria in West Africa. 82 \% of Africa's power comes from the northern and southern regions alone, with three-quarters coming from five countries - Egypt, South Africa, Libya, Morocco and Algeria. Current production in Africa is of the order of 76 $\mathrm{TWh} / \mathrm{yr}$, of which the leading producers are Egypt and Mozambique with $11 \mathrm{TWH} / \mathrm{yr}$.

The gross theoretical potential is $4,000 \mathrm{TWh} / \mathrm{yr}$, while the technically feasible potential is $1,750 \mathrm{TWh} / \mathrm{yr}$. The economically feasible potential is 1,000 TWh/yr. Current installed capacity is 20,300 MW and Hydro under construction is greater than 2,400 MW.

The region possesses some of the largest watercourses in the world (the Nile, the Congo, the Niger, the Volta, the Zambezi), and whilst hydroelectricity is by far the single largest source of electricity in a number of countries (see below), the resources remain largely untapped. An example is that of Cameroon which has hydro potential of up to $115 \mathrm{TWh} / \mathrm{yr}$ and yet installed hydro capacity currently stands at less than $800 \mathrm{MW}$.

The feasible hydroelectric potential in the Democratic Republic of Congo alone is reported to be sufficient to provide three times as much power as Africa presently consumes.

Approximately $50 \%$ of power in Africa is generated from coal-based facilities, although this figure is projected to decrease to $36 \%$ by 2020 . Hydro is the significant contributor in many countries and can be a major contributor to the future growth in generation. Current contribution is seen in Figure 2.5.

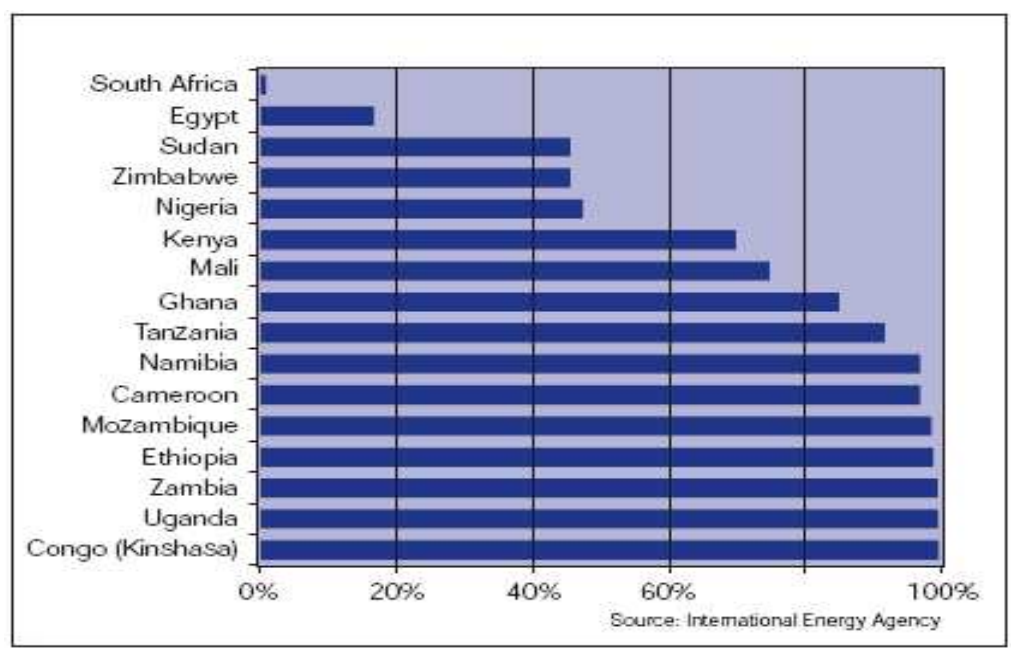

Fig. 2.5. Contribution of Hydropower to net Electricity Generation 2002[7] 
There are significant barriers to development, among them the lack of transmission facilities, the somewhat unpredictable weather patterns in parts of the Continent, and the low level of development at present.

Power sharing, through transmission interconnection will provide a substantial boost to the continent's development. It is becoming more prevalent in recent years. Development in regional economies, such as the formation of the Southern African Democratic Community (SADC) and the Economic Community of West African States (ECOWAS) has also encouraged the export and import of power. South Africa, who has surplus power, is able to operate more efficiently.

Regional sharing has occurred on an informal basis, and on a more formalized basis, such as with the Southern African Power Pool (SAPP), where a number of countries have been linked and purchase power at regulated prices. Countries linked through the SAPP network are: South Africa, Mozambique, Zimbabwe, Zambia, Namibia, Botswana, the Democratic Republic of Congo, Swaziland, Tanzania, Lesotho and Malawi. Kenya and Tanzania may connect to the Zambian power grid, which would bring Kenya into the SAPP. Ongoing connection is a goal of projects initiated and implemented by the New Partnership for Africa's Development (NEPAD), an initiative that sees investment in Africa's infrastructure as a high priority. All NEPAD power projects are aimed at boosting electrical power generation, distribution and transmission in Africa.

South Africa, Ghana and Zambia are the biggest net exporters of power. Further discussion on transmission can be found later.

The extremes of precipitation also constitute a problem for the development of hydroelectric in parts of Africa. Droughts in East Africa in 1999-2000 had a serious impact on the hydroelectric facilities in the region, with Kenya in particular suffering from severe power shortages. Ghana's existing large hydroelectric facilities (Akosombo and Kpong) were also adversely affected by droughts during the late 1990's. However, droughts tend to affect regions, and countries, at different times to others. Improved transmission would allow countries experiencing power shortages to import electricity from other regions recouping the cost of these imports when hydroelectric power production attains its design level by exporting.

The low level of economic development also presents a challenge to power developers - a chicken and egg situation. Africa's electricity consumption is expected to grow at a rate of $4.4 \%$ per year over the next 25 years, which is low compared to that experienced by the South East Asian (Tiger) economies, but will nevertheless require capacity expansions of 270 GW by 2030. The expansion is of course dependent on the robustness of the regional economies, which - in the case of sub Saharan Africa - have had recent growth rates in excess of $4 \%$. Renewed interests in the region's oil sector, with the United States and China in particular vying to take significant portion of their oil from Africa, is expected to reinforce this growth. 
The potential for hydro is mainly focused in central and eastern Africa. Potential for hydro capacity growth is everywhere, but completely dominated by the Democratic Republic of the Congo, Ethiopia, Madagascar, and the Cameroons as seen in Figure. 2.6.

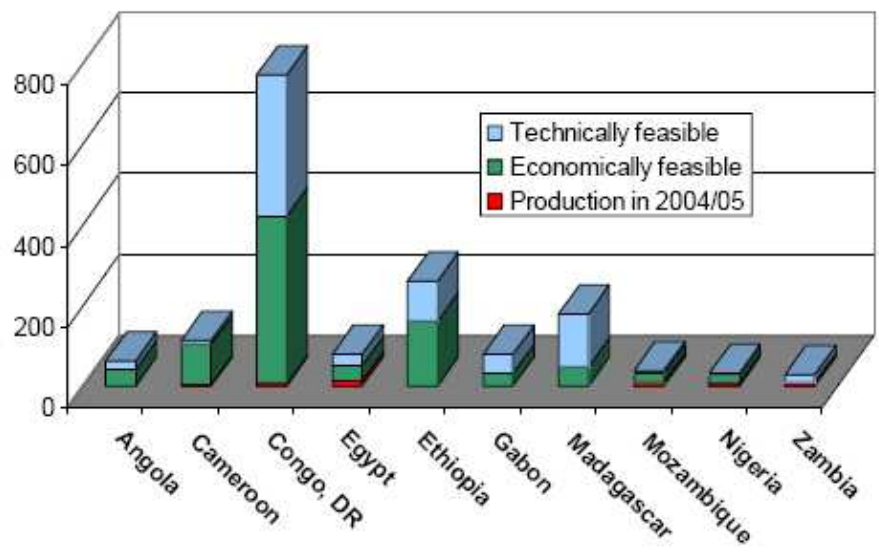

Fig. 2.6. Estimated Potential for Hydropower in Selected African Countries (TWh/yr)

The overwhelming potential (of $774 \mathrm{TWh} / \mathrm{yr}$ ) of the Democratic Republic of the Congo deserves a special mention.

The enormous potential of the Congo River could play an important role in providing power to Central and Southern Africa, as well as exporting electricity to North Africa and possibly Southern Europe. The Congo River accounts for nearly 30\% of Africa's surface water reserves

The "lions share" of the available potential of the Congo River is at the series of rapids at Inga. Development at Inga is preferred because the specific topography leads to relatively benign environmental impacts, the ultimate capacity of 39,000 MW is attractive, and the huge area of the drainage basin is a guard against overwhelming drought.

The Democratic Republic of Congo currently has 1,775 MW of capacity at its two Inga hydroelectric facilities completed in 1972, and in 1982 respectively. Inga provides power to the DRC, the Republic of Congo's (Congo) and Southern Africa - including Zambia, Zimbabwe and South Africa.

The Energy Ministry, DRC estimates that the country earned \$500,000 monthly in 2001 from its energy exports.

Increasing the generating capability of the Inga facility is high on the priority list. Completion of the upgrading of Inga 1 and 2, together with the construction of Inga 3 slated to have a capacity of 3,500 MW would provide enough excess generating capacity for the creation of a new regional electricity export scheme. 
At the heart of the Inga proposals however is the proposed Grand Inga scheme that would be the largest generating facility in Africa. The construction of Three Gorges Dam, in China, has reawakened hope that Grand Inga can be constructed. The project with a capacity of 39,000 MW, in 53 units, would be nearly as large as South Africa's existing generating capacity, and provide the possibility for a pan-African electricity-exporting project.

The World Energy Council has articulated the goals as

"The ultimate objective of Grand Inga is to bring affordable and clean energy to the African continent to facilitate economic development to improve the standards of living. It offers a unique opportunity to move the African continent closer to achieving its sustainable development goals."'

There are other proposed regional hydro projects but the potential is focused on Grand Inga

\subsubsection{Ethiopia}

Ethiopia has a potential for approximately $161 \mathrm{TWh} / \mathrm{yr}$ and has embarked on a series of projects to try to develop its enormous potential. The resources are second only to the Congo in Africa.

Substantial hydro capacity is set to be developed. Hydro schemes already contribute 670 MW out of the $713 \mathrm{MW}$ of capacity on the national grid but the government has finally succeeded in attracting investment in new hydro projects. Currently the $435 \mathrm{MW}$ Beles, 420 MW Gilgel Gibe II and 300 MW Tekeze hydro projects are all being developed by private sector companies.

Ethiopia possesses a host of other potential large-scale hydro sites and so could become a massive electricity provider to large swathes of Africa that are currently power poor. The Ministry of water resources estimates the country has more than 30,000 MW of untapped economically feasible hydroelectric potential. Two that have recently been funded for study are the 896 MW Baro scheme and the 1,000-1,600 MW Karadobi project. The Chemoga Yeda I and II (440 MW), Halele Werabesa I and II (374 MW) and Aleltu East (189 MW) are also currently in the planning stage.

\subsubsection{Uganda}

Uganda already has two hydroelectric schemes on the stretch of Nile within the country between Lake Victoria and the Sudanese border: the 180 MW Nalubaale project, previously called Owen Falls, and the 120 MW Kiira dam scheme, which was brought on stream in 1999. The Bujagali project is set to be completed by 2011 at an estimated cost of US\$ $800 \mathrm{M}$

\subsubsection{Zambia}

Zambia continues to seek ways to increase generating capacity through public/private partnerships. Construction of the Kafue Gorge Lower Hydroelectricity facility (installed capacity 750-900 MW) is estimated to cost more than US\$1 B and development partners have been called upon to support the Government in implementation. 
The existing 900 MW Kariba North Bank power station is to be expanded by an additional $360 \mathrm{MW}$. In addition the 120 MW Itezhi-Tezhi will be initiated shortly.

\subsubsection{Mozambique}

Cahora Bassa northern expansion (550 MW). Mozambique is seeking to embark on the construction of a 1,400 MW hydropower plant on the country's Zambezi River at Mphanda Nkuwa which is estimated to cost US\$ 1.1 B to add to the Cahora Bassa station, which lies upstream of the new site. The Chinese have pledged to provide funding.

\subsubsection{Ghana}

Ghana has identified 17 Hydropower sites, but only two have so far been developed, principally for Aluminum production (Akisombo - 1,038 MW and Kpong - $160 \mathrm{MW}$ ). The government of Ghana has created a development company to implement $400 \mathrm{MW}$ of the hydro project at an estimated cost of US\$ 620 Million. The 400 MW But hydro project at an estimated cost of US\$ 620 Million. The rest of the potential remains to be implemented.

\subsection{Latin America}

Latin America is the third of the major regions that provides significant and valuable development opportunities for hydropower implementation.

Of all regions, perhaps the developing economies of Latin America and particularly South America are most reliant on Hydropower, but there remain many exploitable resources untapped.

As mentioned Brazil is one of the countries with the most reserves, but there remains many projects in Brazil and in these other principal markets:

\subsubsection{Argentina}

Argentina's gross theoretical hydropower potential is reported to be 354,000 GWh/yr, and so far about $26 \%$ of the potential has been developed. At present there are $9,921 \mathrm{MW}$ of installed capacity, with a significant part of the capacity in the projects it shares with Uruguay (Salto Grande) and with Paraguay (Yacyreta). Although it is reported that there are no projects presently under construction, some 2,400 MW of capacity is in planning - again focused on bi-national schemes with Brazil and Paraguay. Argentina provides an excellent example of developments that can be achieved across borders.

\subsubsection{Brazil}

Brazil gross theoretical capacity exceeds 3,000 TWh/yr of which it is postulated that 800 TWh/yr can be developed. Brazil has an installed capacity of approximately 71,000 MW, including the massive Itaipu project (shared with Paraguay), and some other very large installations. Approximately 5,000 MW of hydro capacity is under construction, and approximately $36,600 \mathrm{MW}$ is in planning stages. 


\subsubsection{Chile}

The installed hydro capacity in Chile is approximately 4,700 MW with only $300 \mathrm{MW}$ under construction. 3,000 MW more capacity is in planning, including Baker (1,000 MW) Pascua (1,200 MW), Neltume (400 MW), Choshuenco (150 MW) and Punilla (100 MW).

\subsubsection{Colombia}

Colombia is relatively well developed with 9,000 MW of installed capacity and another $10,000 \mathrm{MW}$ in planning. The country enjoys a theoretical potential of 1,000 TWh/yr, but the exploitable is only $20 \%$ of that. The current construction will only add $660 \mathrm{MW}$ however. The capacity under planning includes Sogamoso (840 MW), Nechi (750 MW), Miel II (410 MW) and Andaqui (705 MW).

\subsubsection{Venezuela}

Venezuela gross theoretical capacity of $320 \mathrm{TWh} / \mathrm{yr}$ has only $130 \mathrm{TWH} / \mathrm{yr}$ that is economically exploitable. At present approximately $74 \%$ of the load is supplied by hydro. Venezuela has invested heavily, most notably in Guri, which includes 10,000 MW of installed capacity. The country's total installed capacity is 14,413 MW with some 2,250 MW under construction. Planned projects total 12,100 MW including Tocoma on the lower Caroni with a projected installed capacity of 2,160 MW.

\subsection{China}

The potential for hydropower in China is huge. The possible capacity is estimated as 402GW of which only $28 \%$ is currently (2005) utilized. The Government plans to triple hydro capacity from the 2004 level (105GW) to approximately 300GW by 2025, and some $50,000+$ MW is under construction. The 2004 and 2005 installed capacity includes approximately 34.5 GW and 38.5 GW respectively indicating an addition of some 7,000 MW of large hydro. The projected $300 \mathrm{GW}$ of hydro in 2025 will represent $30 \%$ of total capacity.

The potential for development in China is so large that it is difficult for this chapter to do justice to the country's resources and plans, so it will concentrate on Southwest China, including the projected AC transmission at $750 \mathrm{kV}$ and UHV and HVDC at $+/-600 \mathrm{kV}$ and higher.

The abundant hydropower resources in Southwest China will be exploited in large-scale in the next three decades. Among a number of large hydropower projects in this region to be completed during the period is a project with two large hydropower stations approximately $90 \mathrm{~km}$ apart on the located on the Jinsha River, the upper reach of Yangtze, named Xi Luodu and Xiang Jiaba. The design of this project has been commenced recently with one hydro power station having the same total capacity as the Itaipu Power Station in Brazil and the other with close to half the capacity of the first. More than half of their power will be transmitted to East China, a distance of close to two thousand kilometers, and the remainder will be transmitted to Central China, a distance about one thousand kilometers. Moreover, further hydropower projects in the region will be developed with the requirement for transmission of large blocks of power too. The merits and drawbacks of different schemes, such as $750 \mathrm{kV}$ or $1150 \mathrm{kV}$ AC power transmission as well as the $+/-600 \mathrm{kV}$ or $+/-750 \mathrm{kV}$ DC power transmission, have been discussed over many years. 


\subsubsection{Precipitation and Topographical Conditions in Southwest China}

Exploitable hydropower resources in Southwest China account for 53\% of China's total. The precipitation and topographical conditions that contribute to hydropower resources in Southwest China are, in summer, the southeast monsoon originating from the Pacific Ocean and the southwest monsoon originating from the Indian Ocean heavy laden with moisture. Annual precipitation is 1500-2000 $\mathrm{mm}$ in this region. The topography of China is high in the West and low in the East. The Qinghai-Tibet Plateau has an average elevation of $4000 \mathrm{~m}$ above sea level with the world's highest mountains, the Himalayas, on its southwestern border. Many rivers originating from the Qinghai-Tibet Plateau or other high mountain ranges flow down to the low plains in the East. Thus, the rivers passing through Southwest China present great opportunities for hydropower development.

In the region, many rivers possess both abundant runoffs and very steep slopes; especially the Jinsha river system in this region, including its main tributaries such as the Yalong and Dadu rivers, which are very rich in hydropower resources and possesses about $40 \%$ of the country's total exploitable hydropower resources.

\subsubsection{Prospective Large Projects in Southwest China}

The exploitable hydropower resources of the Jinsha River System are shown in Table 2.4. Among them the Xi Luodu Hydropower Station will contain 18 generating units, $700 \mathrm{MW}$ each, and the Xiang Jiaba Hydropower Station will contain 8 generating units, $750 \mathrm{MW}$ each. Some others in Southwest China are shown in Table 2.5.

\begin{tabular}{|l|l|l|l|l|}
\hline River & $\begin{array}{l}\text { Length } \\
\mathbf{k m}\end{array}$ & $\begin{array}{l}\text { Total Head } \\
\mathbf{m}\end{array}$ & $\begin{array}{l}\text { Economically } \\
\text { feasible } \\
\text { capacity (GW) }\end{array}$ & $\begin{array}{l}\text { Annual } \\
\text { Energy } \\
\text { TWhr }\end{array}$ \\
\hline $\begin{array}{l}\text { Jinsha main } \\
\text { stream }\end{array}$ & 3481 & 5142 & 58.91 & 323.4 \\
\hline Lower Jinsha & 1326 & 1680 & 50.33 & 274.7 \\
\hline $\begin{array}{l}\text { Yalong main } \\
\text { stream }\end{array}$ & 1571 & 3870 & 22.16 & 135.5 \\
\hline $\begin{array}{l}\text { Dadu main } \\
\text { stream }\end{array}$ & 1062 & 4177 & 20.46 & 108.8 \\
\hline
\end{tabular}

Table 2.4. Exploitable Hydropower Resources of the Jinsha River System

\begin{tabular}{|l|l|l|l|l|}
\hline River & $\begin{array}{l}\text { Length } \\
\mathbf{k m}\end{array}$ & $\begin{array}{l}\text { Total Head } \\
\mathbf{m}\end{array}$ & $\begin{array}{l}\text { Economically } \\
\text { feasible } \\
\text { capacity (GW) }\end{array}$ & $\begin{array}{l}\text { Annual } \\
\text { Energy } \\
\text { TWhr }\end{array}$ \\
\hline Wujiang & 1310 & 3418 & 8.56 & 42.1 \\
\hline Yuanshui & 1022 & 1462 & 3.49 & 15.6 \\
\hline lancang & 2153 & 4583 & 20.88 & 113.3 \\
\hline
\end{tabular}

Table 2.5 Exploitable Hydropower Resources of other River Systems in SW China 
On the Yalong main steam, near the confluence of the Yalong and the Jinsha, there exists already a large project Ertan, containing six units, $550 \mathrm{MW}$ each. Hydropower developments along the Jinsha River System over the next three decades are depicted in Table 2.6.

\begin{tabular}{|l|l|l|}
\hline Project & Capacity & Commissioning \\
\hline Xi Luodu & 12.6 & 2020 \\
\hline Xiang Jiaba & 6.0 & 2025 \\
\hline Hutiaoxia & 6.0 & undecided \\
\hline Baihetan & 12.5 & undecided \\
\hline Wudongde & 7.4 & undecided \\
\hline Jinping & 3.8 & Around 2020 \\
\hline Pubugou & 3.3 & Around 2020 \\
\hline
\end{tabular}

Table 2.6. Major Developments in the Jinsha River System

\subsubsection{Associated Transmission}

Different schemes for the transmission of hydropower from the two power stations have been discussed in recent years including an all HVDC, and all HVAC and a hybrid with HVDC being used for transmission to East China, while Central China receives power via HVAC. The selection of which system to use is critical, particularly in the light of the very large blocks of power to be moved. Some important correlated issues, such as the rational overall arrangement for nationwide power grid interconnections, determination of the highest voltage level going to be introduced in the coming three decades, etc., will be investigated and studied more carefully, and more widely debated before selecting the alternatives for the power transmission.

\subsection{Transmission}

Although all large-scale generation have constraints on location, such as ease of delivery of high volumes of fuel, and the desirability to be remote from centers of population, hydro is significantly constrained by the topographical requirements of the development. Thus the transmission of power from hydro projects often assumes greater importance (than for a fossil fuel project) in the assessment of feasibility and in the final cost of a project.

It is a challenge for any single hydro plant - other than those massive developments - to support the transmission infrastructure required for the overall utilization of hydro in a region or country, so mechanisms must be found to enable this infrastructure to be put in place independent of the individual generation investments.

In addition regional initiatives and joint investments by governments and international agencies can result in more attractive investments for those considering generation investment.

In additions interconnection of national and regional systems allows generation to iron out different demand patterns and different generation mixes to the communal benefit of all. A prime example of this cooperation is the interconnected transmission on the west coast of the USA enabling the USA and Canada to jointly benefit from the development of the upper reaches of the Columbia River, and the firming of the power in the lower reaches. 
The countries of the EU are also significant exporters and importers of power even though each of them has a different architecture of their power generation.

Table 2.7 indicates the percentage of each country's production that is imported and exported:

\begin{tabular}{|c|c|c|}
\hline Nation & $\begin{array}{l}\text { Export/ } \\
\text { Production }\end{array}$ & $\begin{array}{l}\text { Import/ } \\
\text { Consumption }\end{array}$ \\
\hline Germany & $6.5 \%$ & $7.4 \%$ \\
\hline France & 14.7 & 0.7 \\
\hline UK & 0.0 & 4.7 \\
\hline Italy & 0.5 & 13.9 \\
\hline Spain & 1.9 & 4.5 \\
\hline Sweden & 6.4 & 5.3 \\
\hline Netherlands & 0.7 & 13.0 \\
\hline EU Total & 6.3 & 6.9 \\
\hline
\end{tabular}

Table 2.7. Import and Export of Power in Europe [8]

In considering the harnessing of untapped hydro throughout the world, the requirement for and the potential for long distance transmission of electrical energy is paramount.

As noted elsewhere, energy transmission may be achieved through HV AC or DC lines. For more than half a century, after the struggle between AC and DC for universal production, transmission and utilization of electrical energy had been won by AC; this position remained unchallenged until the 1950s. At that time the availability of large, high powered, mercury arc rectifiers gave birth to a new interest in the application of DC for transmission purposes. One of the primary drivers for this reawakening of interest was cost - the historical justification for many of the early HVDC schemes.

The explanation is illustrated in Figure 2.7, which plots the cost of AC and DC transmission against distance. Because DC requires only two conductors (or only one if ground return is used) compared to three for normal three-phase AC transmission, the incremental cost of conductors is reduced in the same ratio. The cost of the supporting towers and insulators is correspondingly also reduced. Finally the transmission losses are also reduced in a similar fashion. These reduced incremental cost advantages are offset, however, by the greatly increased cost requirements of DC converter stations in comparison to AC substations. 
Nevertheless, if the transmission distance is sufficiently long a "breakeven distance" is reached beyond which HVDC becomes more economical than AC.

Depending on the prices of copper and aluminum as well as other materials, the threshold distance changes year by year, but the approximate breakeven point is $800 \mathrm{~km}$ for EHV overhead lines. However, for underground or submarine cables, which cost an order of magnitude more than overhead lines, the breakeven distance is only of the order of $50 \mathrm{~km}$

Hence the new technology was born and was given greater impetus, both technically and economically, by the introduction of thyristor technology and other subsequent developments.

However, it is not only for cost reasons that HVDC proves beneficial to the transmission process. Sometimes it presents the only possible option:

- Long sea crossing (Cable charging current prevents the use of AC transmission over distances $>75-100 \mathrm{~km}$, depending on voltage)

- Frequency conversion (i.e., $50 \mathrm{~Hz}$ to $60 \mathrm{~Hz}$ )

- Where synchronization is impossible (i.e., due to stability reasons or frequency control regimes).

AC power transmission sometimes exhibits stability problems in long overhead transmission lines.

Examples from past, present and future of how HVDC has and might benefit long distance transmission - and the inclusion of substantial hydro in the generation mix - are presented below.

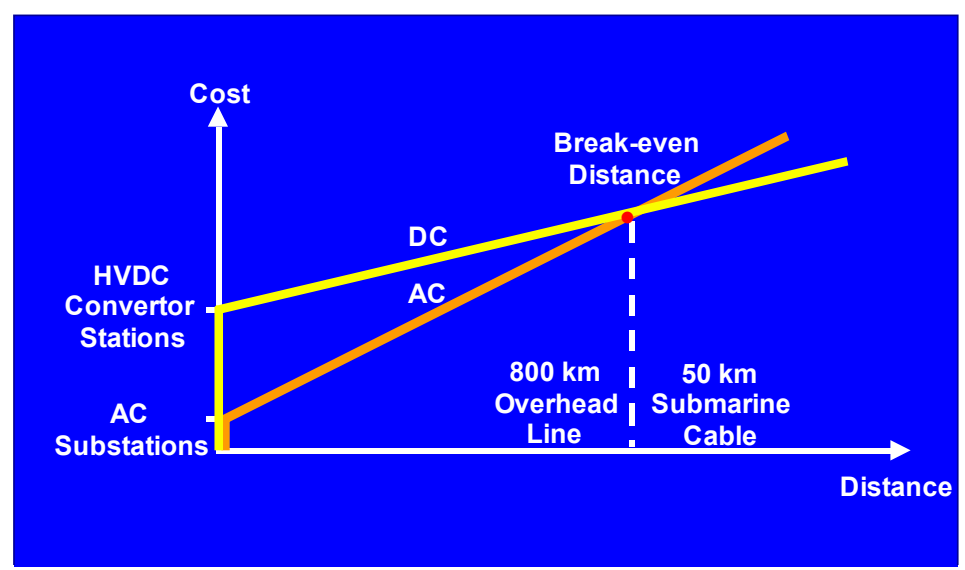

Fig. 2.7. Comparison of Costs of HVDC and HVAC transmission

Planners and interested parties have developed many proposals throughout the world for the creation of HV grids, and the interconnection of these grids, to facilitate export and 
import of electricity. Many such exports and imports would be provided by Independent power producers.

A legacy of the colonial period in the developing world has been that the transmission networks of each state are often isolated from those of neighboring countries. Since independence, many national power companies have struggled to maintain power supplies to the main towns and progress on extending power grids has suffered, with the development of cross-border transmission interconnectors well down the priority list. Malaysia and Singapore are an example however of countries that interchanges electricity at peak times. Cross border transmission could have great benefit - Japan's annual load factor is for example approximately 55\% leading to great inefficiencies in supply capability for the peak demand. Typical advantages articulated for the extension of the Indian grid described below also apply to inter country's connection;

\section{Economic}

- Shared peak generation and exchange of energy means reduced generation plant margins in each region

- Peak load diversity permits export of surplus energy and operation of thermal plant at base load with higher efficiency

- Investment in new generation is avoided (or postponed) at a cost of only one fifth

- Improved reliability of the AC system through availability of emergency power

- $\quad$ Reduced industrial disruption due to load shedding.

\section{Environmental}

- Fuller use is made of seasonal high rainfall run-off, transferring extra hydro capacity to the other regions/nations

- By importing thermal energy in time of drought precious hydro resources are conserved and more efficiently managed

- Less coal burning is achieved in non hydro countries/regions if secondary energy from the hydro resources can be imported

- Construction of fewer generating stations is possible by sharing generation reserves for outages and peaks, reducing environmental impact in all regions/nations.

Some countries are focusing on the transmission aspect of development, such as Laos because "Electric power production contributes both foreign currency accumulation and domestic social progress."

Within countries some major transfers of electricity are in various stages of development, including the proposed cable between Sarawak (east Malaysia) and peninsular Malaysia. 


\subsubsection{North America}

The largest capacity HVDC scheme in North America, and one of the two earliest, is the Nelson River Scheme in Canada (Figure 2.8). The two bi-poles of this scheme carry 3,800MW over a distance of $900 \mathrm{~km}$ from the hydro stations on the Nelson River in northern Manitoba to Dorsey Converter Station near Winnipeg. Some of this energy is dispatched further south into the industrial heartland of the US Midwest. The original bi-pole 1 employed mercury arc valves, but Pole 1 was refurbished and upgraded in 1990-1992 with modern thyristor technology. Not only does this HVDC scheme provide long distance bulk power transfer but also Power Oscillation Damping to assist with frequency control and stability of the receiving AC system.

Contemporary with the Nelson River Scheme is the Pacific Intertie that transports 3,100 MW of Columbia River hydro energy from Celilo in Oregon to Sylmar, near Los Angeles, $1,400 \mathrm{~km}$ to the south. This HVDC tie runs in parallel with EHV AC transmission and can also be used to provide additional control and stabilization to the Pacific Coast AC system. Similar capabilities are provided by the 1,920 MW Inter Mountain HVDC Project, which brings hydro energy from the Boulder Dam on the Colorado River across $800 \mathrm{~km}$ into Los Angeles.

The final North American example is the 2,250 MW Quebec - New England HVDC Project that taps the rich hydro resources of the James Bay region of northern Quebec. This scheme is unusual for being multi-terminal: feeding its power not only $1500 \mathrm{~km}$ south to Sandy Pond in New England, but also providing vital supplies to the metropolis of Montreal via an intermediate converter station at Nicolet.

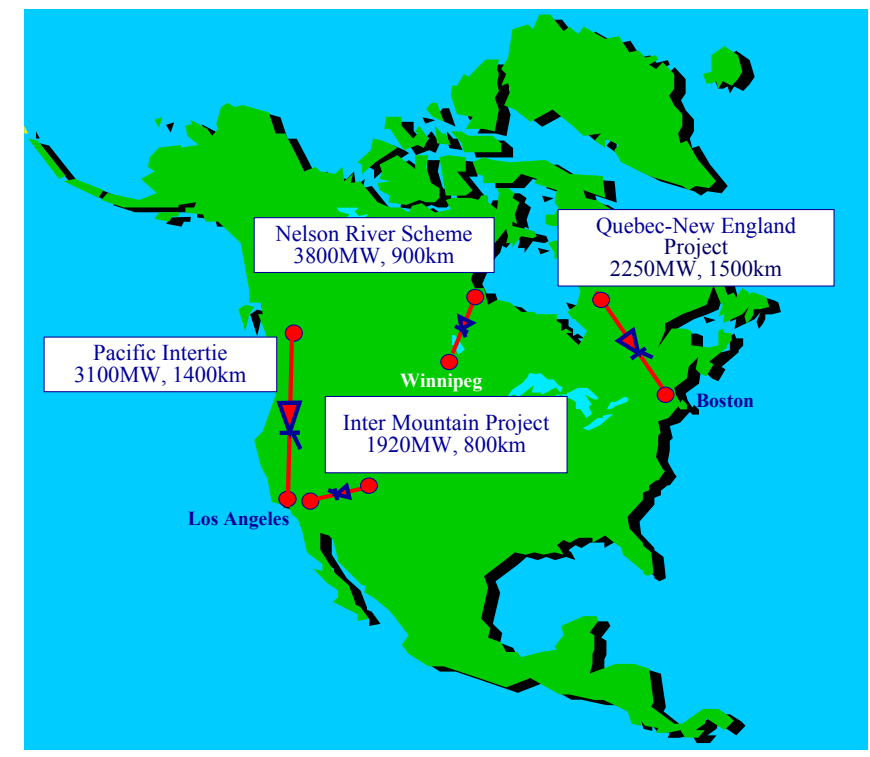

Fig. 2.8 Canadian HVDC Transmission 


\subsubsection{South America}

South America is the location of the world's largest power station, the hydroelectric installation at Itaipu on the border of Brazil and Paraguay. Originally 12,000 MW, but recently upgraded to $13,400 \mathrm{MW}$ by the addition of two $700 \mathrm{MW}$ generating units, the bulk of this capacity is fed to the industrial center of Brazil near Sao Paolo. The distance is $800 \mathrm{~km}$ and around half of the energy is transmitted by two $750 \mathrm{kV}$ AC circuits. However, for stability reasons it is not possible to transmit the total output by $\mathrm{AC}$ and 6,300 $\mathrm{MW}$ is supplied over two bi-poles of $\pm 600 \mathrm{kV}$, which is the world's highest DC voltage to date. The stabilizing effect of HVDC's fast acting controls ensures the stability of the overall transmission. Note also the ability of DC to transmit a similar capacity at a lower voltage than AC - and in a smaller transmission corridor.

Brazil is presently experiencing a crisis of energy supply and is in urgent need of reinforcement from both internal and external resources. Some of its neighbors (Argentina, Uruguay and Venezuela) are rich in hydro capacity, but suffer from problems of extreme remoteness and/or a different operating frequency. Brazil, a minority among South American nations, employs $60 \mathrm{~Hz}$ whereas its neighbors operate at $50 \mathrm{~Hz}$. Thus, the many recent and proposed in feeds to Brazil, whether from near or far, are by means of HVDC both long distance and back-to-back. These include existing and future interconnections with Argentina and Uruguay, together with proposed links with Venezuela. There has also existed for many years a Brazilian dream to tap the vast untapped hydro resources of the Amazon region, for which HVDC would be the prime choice on account of the extreme distance. Brazil, however, is not alone in South America in having its hydro resources located remote from the load centers. Chile is rich in hydro in the Andes Mountains of Patagonia in the south of that exceptionally long country. The Chileans are therefore studying the economics of transmitting this energy by means of HVDC to the capital Santiago.

\subsubsection{Scandinavia}

Scandinavia, the mountainous north of Europe, is rich in hydro potential tapped and untapped. Continental European industry, far to the south, is hungry for cheap energy and has looked to these resources for many years. In this case the distances are not extreme in overhead line terms but the difficulties remain two-fold:

- In some cases lengthy sea crossings

- In most cases unsynchronized AC systems.

All of the examples considered necessitate sea crossing by submarine cable. Although the shorter crossings are of insufficient length to either justify or necessitate the use of DC the complication exists that the large Scandinavian power pool (Nordel) cannot be synchronized to the Western European power system due to differences in operating regimes and, in particular, in frequency control strategies. Hence HVDC is in all cases the only option for tapping these hydro resources. 
The existing schemes in the category of hydro deliverers are five. There are also other HVDC schemes that are not discussed, as their functions are simply interconnectors. The five are (Figure 2.9):

$\begin{array}{lll}\text { Skagerrak, } & 1,190 \mathrm{MW}, & 240 \mathrm{~km} \\ \text { Konti-Skan, } & 550 \mathrm{MW}, & 180 \mathrm{~km} \\ \text { Fenno-Skan, } & 500 \mathrm{MW}, & 200 \mathrm{~km} \\ \text { Baltic Cable, } & 600 \mathrm{MW}, & 260 \mathrm{~km} \\ \text { Sweden-Poland, } & 600 \mathrm{MW}, & 230 \mathrm{~km} .\end{array}$

Four of these have their primary purpose as the delivery of cheap hydro energy to continental Europe. Their secondary purpose, for which they are employed on a seasonal basis when water levels are low in the summer months and on a daily basis in winter when the domestic electric storage heating loads are high in Scandinavia, is to utilize available European thermal resources to conserve hydraulic stocks in a cost-effective manner. The exception to this pattern is the Fenno-Skan link whose purpose is to deliver hydro energy from Finland to Stockholm in Sweden.

The recent deregulation and privatization of European utilities has encouraged the increase in cross-border energy trading. Thus, many new projects have been initiated to deliver the abundant hydro resources of Scandinavia to industrial Europe. Moreover, advances in cable technology now permit much greater lengths of submarine cables, permitting delivery to even further destinations. Of the following three projects the first two have been ordered but not yet commenced and the third is currently at the bidding stage:

$\begin{array}{lcc}\text { NorNed, } & 600 \mathrm{MW}, & 650 \mathrm{~km} \\ \text { Viking Cable, } & 800 \mathrm{MW}, & 600 \mathrm{~km} \\ \text { North Sea Interconnector, } 1,200 \mathrm{MW} \text { or } 800 \mathrm{MW}, & 700 \mathrm{~km} .\end{array}$

The final example is uncertain until economic circumstances change, on account of the distance involved and the difficulty of the cable route due to extreme depth and currents in the Faroes Trench. This is the long discussed Iceland to Scotland link $(950 \mathrm{~km})$ for which a single cable would permit the transport of $800 \mathrm{MW}$ and two cables $1600 \mathrm{MW}$. Iceland has vast untapped hydro resources together with substantial geothermal reserves, but access thereto must continue to remain some way in the future. 


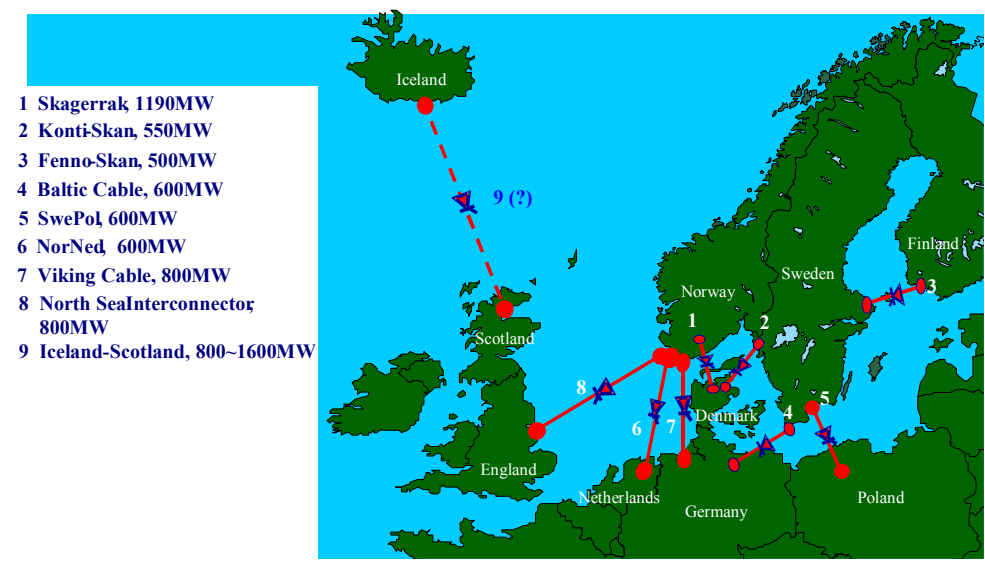

Fig. 2.9. Scandinavian Connections

\subsubsection{India}

In the case of India the examples of HVDC facilitating the release of hydro resources are of a completely different nature to those that have been considered so far. India comprises four distinct regions each with its own independent electric power system operating nominally at $50 \mathrm{~Hz}$ but, because of an endemic national energy shortage, these systems are subjected to sustained variations in frequency between $47 \mathrm{~Hz}$ and $52 \mathrm{~Hz}$ on a daily basis. Historically these regional systems were not interconnected because, although regional interconnections are vitally necessary to share scarce national resources, it was not possible to connect them synchronously because of their disparate frequency control regimes and for reasons of stability. The PowerGrid Corporation of India was charged by the Indian government with establishing a National Grid to facilitate the sharing of resources in order to avoid or minimize the problems of energy shortage. The only solution was to base the grid on asynchronous, HVDC interconnections. In this case the interconnections are of zero distance, with the AC-DC-AC converters located in the same station in a Back-to-Back configuration. To date the following ties link the regions (Figure 2.10):

- Vindyachal,

$500 \mathrm{MW}$

- Chandrapur,

$$
2 \times 500 \mathrm{MW}
$$

- Visakhapatnam, $500 \mathrm{MW}$

- Sasaram, 500 MW (entered service 2002).

Repeat installations are planned for Visakhapatnam and Sasaram, with the bidding process already initiated. The South region is relatively rich in hydro resources while the generation in the other regions is essentially based on thermal with limited capacity. The benefits introduced by these links are as both economic and environmental: 


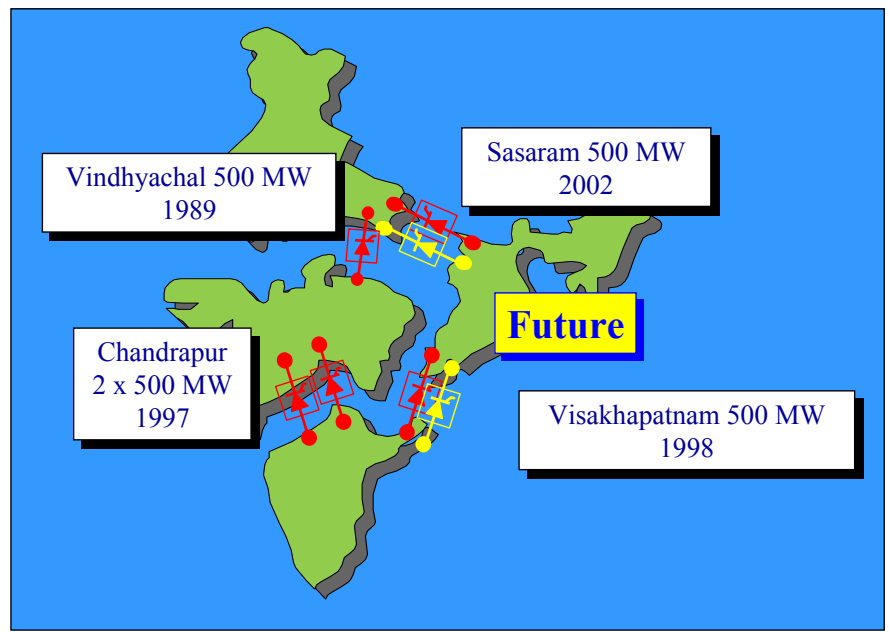

Fig. 2.10. Indian HVDC Connections

\subsubsection{China}

China is a country of almost continental dimensions. Its energy resources, both hydro and thermal, are located in the center or Far West whereas the centers of population and industry are located essentially on the coast. The distances across which bulk energy must be transported are enormous, ranging from hundreds of $\mathrm{km}$ to more than 2,000 km. The first applications of HVDC link to provide access to remote hydro resources were (Figure 2.11):

- Gezhouba - Shanghai, 1,200 MW $700 \mathrm{~km}$

- Tian - Guang, 1,800 MW $970 \mathrm{~km}$.

However the biggest driver for expansion of this process has been the initiation of the Three Gorges Dam project on the Yangtze River, exceeding Itaipu to become the world's largest power station, with a capacity of $18,000 \mathrm{MW}$. In order to evacuate this vast capacity the following schemes have been ordered or initiated:

- Three Gorges - Shanghai (I), 3,000 MW $\quad 800 \mathrm{~km}$

- Three Gorges - Guangzhou, 3,000 MW 1,000 km

- Three Gorges - Shanghai (II), 3,000 MW $800 \mathrm{~km}$.

Export of China's resources to neighboring countries is also under consideration, utilizing the ample hydro potential of Yunnan province to supply the needs of Bangkok in Thailand:

- Yunnan - Bangkok, 2,000 MW 1,100 km.

Many more projects have already been identified and wait in their turn for the allocation of the necessary priority and resources for development. 


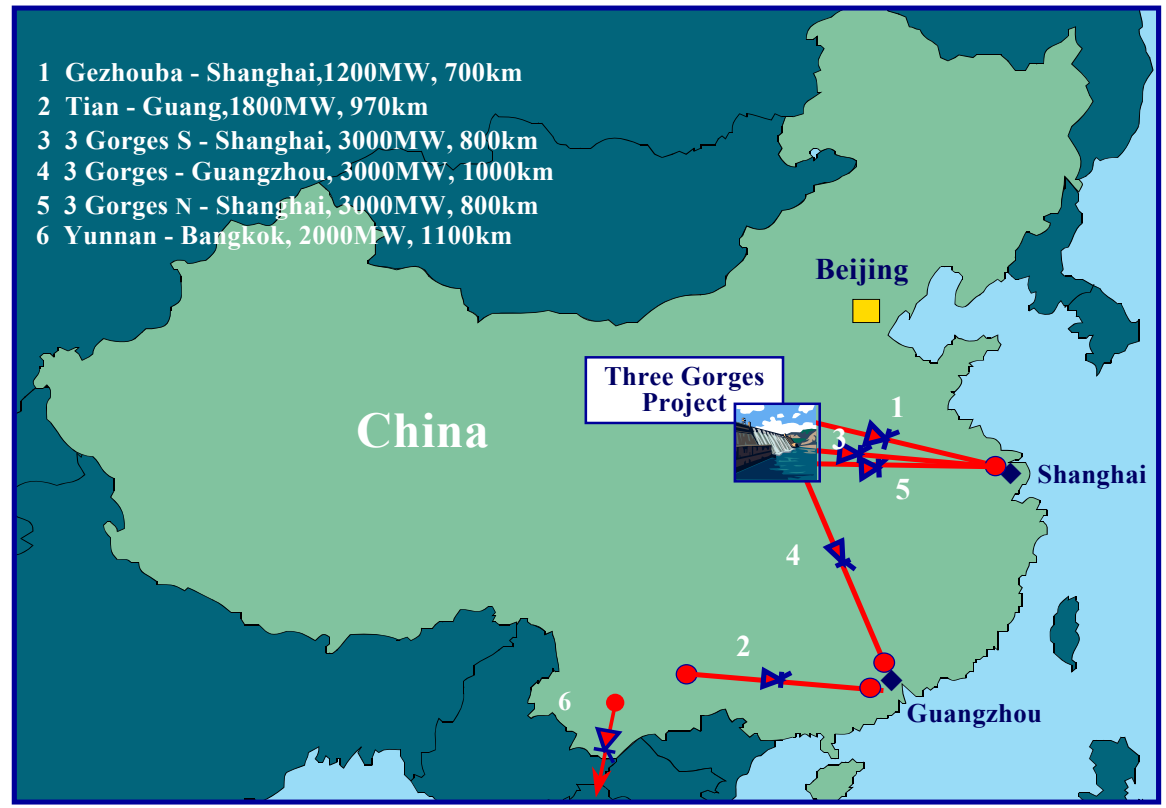

Fig. 2.11. Chinese HVDC Connections

\subsubsection{Africa}

Regional transmission projects in Africa are currently being supported by NEPAD.

The NEPAD strategic framework document arises from a mandate given to the five initiating Heads of State (Algeria, Egypt, Nigeria, Senegal, and South Africa) by the Organization of African Unity (OAU) to develop an integrated socio-economic development framework for Africa. The 37th Summit of the OAU in July 2001 formally adopted the strategic framework document).

Proposed Regional Transmission Projects many of which will be HVDC because of the distances and the significant energy flow are shown on Figure 2.12 and include:

- Upgrade of Zambia -DR Congo -S. Africa Interconnection

- Zambia-Tanzania Interconnection

- Namibia-Botswana Interconnection

- W. Africa Grid Network and Power Pool. 


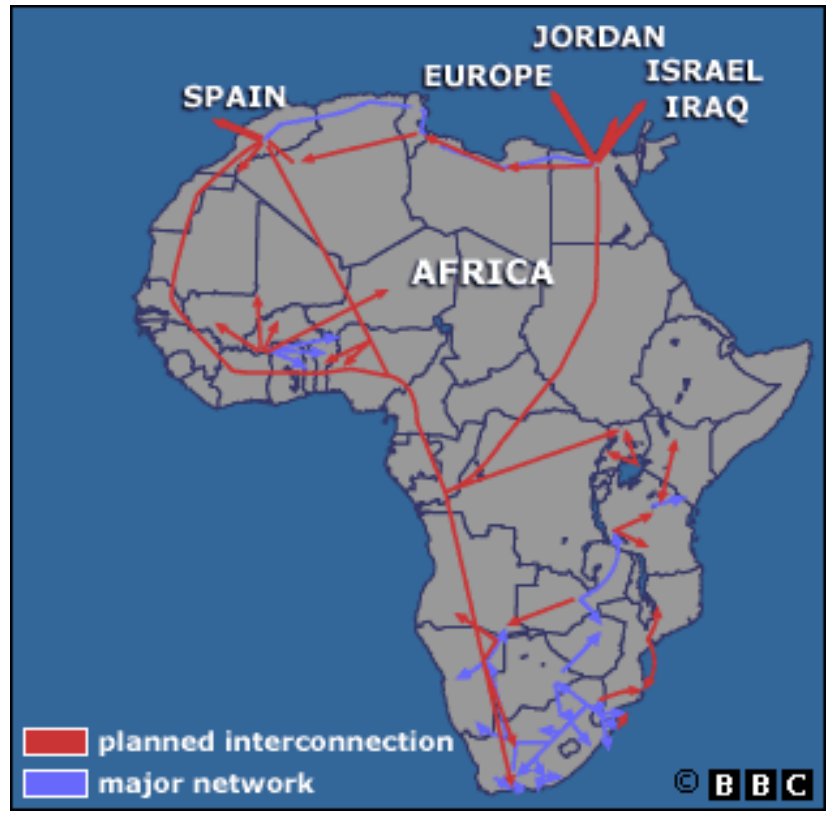

Fig. 2.12. African Transmission

\subsubsection{South East Asia}

A prime example of a regional project that is gradually moving forward is one sponsored by ASEAN within which a Power Forum has developed a Memorandum to increase the electricity trade. Within this forum, study groups are investigating the future of an ASEAN power system (Figure 2.13).

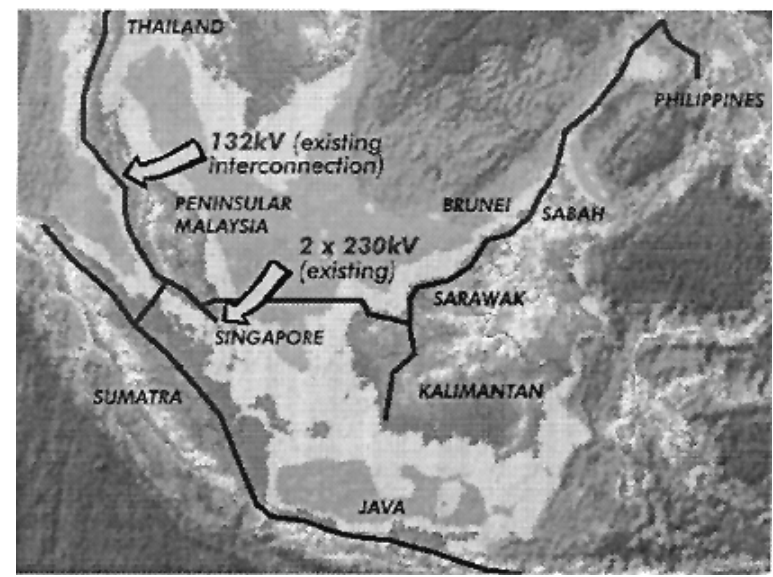

Fig. 2.13. ASEAN Power System Interconnection 


\subsection{Environmental}

The development of water resources by humanity - including the development of hydro resources - has a range of environmental effects beyond those intended. These effects can be beneficial, or adverse, and are not simply limited to the aquatic environment. The environmental lobby has driven the debate on these matters and there has been an almost inexhaustible litany over the last few decades on the denigration that hydroelectric power plants (and in particular the dams that are an integral part of many storage schemes) may have reeked on the environment, fauna and flora and indigenous peoples. Meanwhile other expanding forms of human activity - not least the generation of electricity using fossil fuels have inexorably continued to move mankind to the crisis that now overwhelms, in the form of irreversible climate change.

The Energy Information Agency at the United States Department of Energy and the World Energy Council monitor global energy consumption on a regular basis. EIA's report, "International Energy Outlook 2000" included a forecast that total energy consumption, worldwide, from all sources, will grow by 60 percent between 1997 and 2020. Consumption was expected to increase from 111,000 TWh/year to 178,000 TWh/year.

When the electricity share of total energy consumption is considered, the increase becomes even more dramatic. The International Energy Outlook 2000 forecast that global consumption of electricity would be 76 percent higher in 2020 than in 1997. Consumption will increase from 12,000 TWh (1997) to 22,000 TWh (2020).

By the year 2050, the world population is expected to increase by 50 per cent, from 6 to 9 billion. Energy consumption per inhabitant per year is generally in correlation with the standard of living of the population. Today the less developed countries in the world, with 2.2 billion inhabitants, have an annual per capita consumption of primary energy 20 times less than those of the industrialized countries (with 1.3 billion inhabitants), and per capita electricity consumption that is 35 times less.

World energy consumption, and especially electricity consumption, will increase considerably during this century, not only because of the demographic pressure, but also because of the development in living standards, The raising of overall global economic prosperity continues to drive the consumption of energy (including generated electricity) to record levels, with electricity consumption anticipated to increase at rates faster than overall energy supply. The majority ( 80 per cent) of energy available today is provided from thermal sources, i.e. coal, gas and oil; but there are growing global concerns regarding the lack of sustainability of these forms of energy that casts doubts their use in a long-term energy strategy.

Developed nations will probably seek more energy - not least for "plug in hybrids" and zero emission electric automobiles - while the rest of the world (which will represent 7 billion inhabitants by 2050 and 78 per cent of world population) will seek the basic energy consuming necessities of life that have been enjoyed for years in the West, such as lighting, refrigerators, treated water, etc.

In this scenario it is not viable to simply exclude hydroelectric power, and methodologies must be put in place to defuse and mitigate the environmental aspects of hydropower 
development. Essentially - just as with all human activity - the concept of sustainability must be significant part of the discussion of power generation as a whole. Under these conditions the incorporation of the most mature renewable, hydro, into the system mix is invaluable.

In comparison with hydropower, thermal plants take less time to design, obtain approval, build and recover investment. However, they have higher operating costs, typically shorter operating lives (about 25 years), are major sources of air, water and soil pollution and greenhouse gases, while providing fewer opportunities for project economic spin-offs. A comparison supplied by Manitoba Hydro is shown in Figure 2.14.

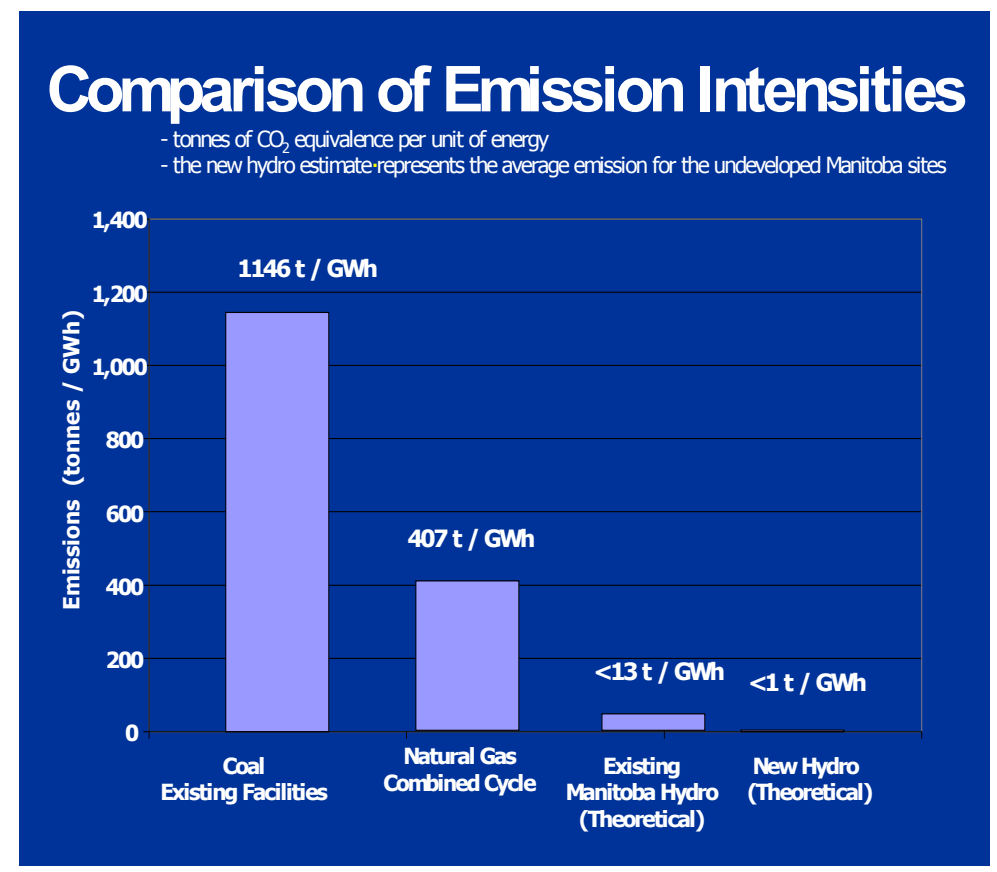

Fig. 2.14 Comparison of Emissions (Manitoba)

The average hydro power plant obviously has a place in a sustainable energy mix, but the perceived problems must be addressed.

In the late 90s an attempt to air all the environmental issues associated with the construction of dams was made by the assembly of the World Commission on Dams (WCD). This body produced a report "Dams and Development - A New Framework for Decision Making" that crafted some guidelines for development of dams. Essentially the guidelines are a restatement of the importance of dialogue with all affected parties, which of course is a central element of a mature democracy.

A recent perspective is that of sustainability, and embracing this approach may hold the key to the implementation of hydropower. 
Key elements of sustainability seem to be hard to define. To date much of the debate around what constitutes "environmental friendly" generation devolves into a debate as to the definition of "green energy", "renewables" and "alternative energy", each with characteristics that make them somehow preferable to "conventional" forms of generation, such as coal-fired, nuclear, or large hydroelectric facilities. Much has been written on this subject without ever finally resolving the question of what types of electric generation technologies are "best". Best, one might ask from whose point of view? Best, according to what criteria? Such debate is endless and of little value. There is no answer to the question "how green is green?" Most jurisdictions include wind power and solar power to be green, but one state in the US (for example) considers combined-cycle gas turbines to be green.

And why - it is reasonable to ask - is large hydro not considered to be "green" by some. It is overwhelmingly renewable. Large hydro has been attacked by various people for a host of sins, including destruction of habitat, species extirpation, social upheaval, and being a source of greenhouse gas (GHG) emissions. It is simple to show that the benefits of large oligotrophic reservoirs capable of multi-year storage of energy, created in steep-sided valleys, vastly outweigh the damage done. Impacts can be amortized over many decades, equal to the life of the facility. Eventually, the impounded riverine system that has become a reservoir adapts to a new kind of ecological equilibrium as a quasi-liminetic system. In contrast, thermal generation produces impacts through gaseous pollutants every hour that the plant runs. Coal plants add ash disposal and mining-related impacts to the list. Emissions can be scrubbed, but they cannot be amortized. Any hydro-based system, whether large or small, has of course associated operating impacts due to flow restrictions, fluctuating reservoir levels, blockage of fish passage and sometime-elevated levels of mercury in reservoirs. These are difficulties that must be dealt with.

Other impacts of large hydro projects, such as habitat destruction and methane production from the decay of submerged plant matter, are harder to deal with. Habitat destruction can never really be compensated for, and any projects that contribute to the extirpation or worse, extinction of species need to be very carefully considered. To put the problem in perspective though, the amount of land areas sacrificed to reservoirs is minuscule compared to that devoted to agriculture and habitation. Is it "worse" to cover existing habitat with cornfields, parking lots, housing and factories than with water?

In the production of methane etc, all large hydro projects must not be treated equally. Methane production is greatest in reservoirs in shallow, tropical regions, and least in steepsided valleys in cold climates. In fact the production of GHG may be less than some indicate. Although there is decomposition of biomass in the waters of a reservoir, recent research in North America [Gagnon, 1999] indicates that the GHG emission factor for hydro plants is typically 30 - 60 times less than factors for fossil fuel generation. Development of half the world's economically feasible hydropower could reduce GHG emissions by about 13 per cent, together with beneficial avoidance of sulphur dioxide (SO2) emissions (the main cause of acid rain) and nitrous oxide emissions. Even including the fuel required to build hydropower stations, a coal-fired plant can emit 1000 times more SO2 than a hydropower system. An analysis has been completed for the Tucurui plant in Brazil, including 'worst case' assumptions concerning the decomposition of flooded biomass and even under these 
worst case assumptions, the emission factor for Tucurui would be five times lower than that for coal plant.

Assuming that a sustainable generation policy includes significant hydro - as argued herein - those environmental effects that need to be addressed when planning and implementing hydro are:

\subsubsection{River Barriers}

An obvious effect of a dam is to form a barrier to movement of fish and other aquatic organisms up and downstream. This problem has been recognized for years, in terms of both the barrier itself, the reduction in water velocity upstream of the dam and loss in spawning habitat. These aspects affect different species and the different life cycle stages of species in different ways. Systems to assist upstream movement, through fish ladders, lifts, locks, trap and haul, etc. have had varying success around the world, and where species numbers have dropped additional methods such as artificial spawning channels and hatcheries have a place etc.

The attempts to assist various salmon species are most well known, but other species with the reverse life cycle, known as catadromous species, including shrimps and eels need to be considered so that the effects of dams minimized.

Much research has been done on the specific risks to different sizes and species of fish. Measures commonly used include fish screens at turbine inlets, and many countries require this by law. Finer meshed screens can be placed at times of year when fish are actively migrating. Various types of self-cleaning screen have been developed to cope with the buildup of debris. Behavioral methods have also been developed to defer fish from the intake, and guide them to the safety of a bypass channel. These include: louvre screens (which generate turbulence), bubble curtains acoustic barriers, electrical fields, and underwater lights [Turnpenny, 1999]. Well-designed behavioral systems (e.g., louvre screens or the latest acoustic screening techniques), can achieve better than 90 per cent exclusion for certain species. However, certain dams have proven to have significant impacts to native fish.

Knowledge from experimental studies about the mechanisms of fish damage in turbines has in recent years led the development of 'fish-friendly' turbines. (Pressure and velocity characteristics within a rotating turbine can be modeled and the probability of different risk conditions estimated).

\subsubsection{Alteration of Flow Regimes and Temperature}

Alteration of the flow regime is particularly acute in large storage reservoirs in climactic situations with accentuated wet and dry seasons, and somewhat less in those used for peaking or daily storage operation. Of course run of river facilities have the least impact.

Alteration is further accentuated if as is often the case there is a diversion component of the project such as for irrigation or water transfer. 
Methodologies and policies exist to try to mitigate these effects as far as possible and should be considered. These methodologies include incremental flow in-stream methodology to determine a reasonable in-stream flow to restrict the effects to downstream fisheries.

Water emerging from a dam tends to be colder, and often has altered levels of dissolved gases, minerals and chemical content, different from those present prior to the dam. The result, in some cases, is the native fish cannot tolerate the new conditions and are forced to relocate, or suffer mortality losses. Temperature variations or excesses can sometimes be mitigated by the drawing off of water from particular levels in the reservoir that avoids the worst stress on indigenous species.

Consideration should be given to ramping rates, particularly for daily cycling and or peaking plants. A downstream reregulating dam can mitigate this, but topography may not allow this solution. It is reported that some success has been achieved by simply "stepping" of ramping.

\subsubsection{Flow Diversion}

When a project includes a significant diversion such as a long canal, or as a secondary factor water is drawn for irrigation or transfer, the problem of mortality of younger, weaker or larval (or egg) states can sometimes be a danger. Proper siting of the diversion, and careful screening will lessen the problem.

\subsubsection{Sedimentation}

Sedimentation from weathered rock, organic and chemical materials being transported in a river can become trapped in a reservoir. Over time these sediments may build up and begin to occupy a significant volume of the original storage capacity. In addition, since they are trapped, the soils cannot continue to refresh the river system downstream of the dam. The lack of the transported sediments may have adverse impacts to sustainable riparian vegetation, and to the continued use of lands for agriculture. It is considered imperative to assess as accurately as possible at the conceptual stage of a project the average annual sediment load entering a reservoir, or passing through a run-of-river project, so that appropriate measures can be taken. A number of measures can be taken such as periodic flushing or dredging from reservoirs (successful flushing has been reported in many countries, and especially in China).

\subsubsection{Nutrients}

The long-term operation of storage facilities can also influence the recruitment of not only sediments but also nutrients and gravel into rivers downstream of reservoirs. The loss affects river productivity; but can be offset by restoration programs.

\subsubsection{Water Quality}

Changes in water quality are potential outcomes from locating a dam in a river. Effects are often experienced both upstream and downstream of a dam. Some of the effects can be increased or decreased dissolved oxygen, increases in total dissolved gases, modified 
nutrient levels, thermal modification and heavy metal levels. Relatively few reservoirs have acute problems, and mitigation measures can be adopted if necessary.

Again the effects are highly dependent on size, shape, depth and operation rules. Narrow reservoirs with high inflows relative to outflows will tend to have minimal effects on water quality. In contrast large reservoirs with greater storage capacity and large surface area subject to seasonal solar gain allow development of seasonal stratification resulting in significant changes in water quality at various depths. At depth - particularly if biomass is present where light does not penetrate sufficiently for photosynthesis, oxygen levels can become depleted.

Solutions to these complications include the removal of biomass by careful clearing before impounding, the use of multi level intakes, and discharge through oxygenating facilities such as Howell Bunger Valves.

Unfortunately an opposite problem may occur from that of lack of oxygen, that is an excess of nitrogen. Deep spillway plunge pools can allow air-entrained water to plunge to a depth at which the pressure is sufficient to supersaturate the water with nitrogen. Simplistically, fish in the area can suffer similar afflictions to that sometimes-affecting deep-sea diver, which is the bends, (known as gas bubble disease in fish).

The solution to this difficulty is to use turbines to discharge and to try to use energy dissipation devices that avoid excessive plunging.

Despite the various attributes of reservoirs that must be addressed, many reservoirs provide an excellent environment for fish that develop in the new, expanded aquatic ecosystems. In several situations game management agencies have stocked fish in and below the reservoir, with high economic or recreational value.

\subsubsection{Social Aspects}

As with other forms of economic activity, hydro projects can have both positive and negative social aspects. Social costs are mainly associated with transformation of land use in the project area, and displacement of people living in the reservoir area.

Relocating people from a new reservoir area is, undoubtedly, the most challenging social aspect of hydropower, leading to significant concerns regarding local culture, reasonable spreading of economic benefit and pain, religious beliefs, and effects associated with inundating burial sites.

While there can never be a 100 percent satisfactory solution to involuntary and resettlement, enormous progress has been made in the way the problem is handled. Developed nations tend to ignore the fact that many of them addressed similar problems of involuntary resettlement (or at least resettlement driven by unstoppable economic forces). Human history has been punctuated by resettlement. The key to this problem is sensitivity and fairness, accompanied by timely and continuous communications between developers and those affected; adequate compensation, support and long term contact. It is vitally 
important to ensure that the disruption of relocation is balanced by some direct benefits from the project.

The countries in Asia and Latin America, where resettlement is a major issue, have developed strategies for compensation and support for people who are impacted, and an increasing number of examples are demonstrating that current strategies may be proving successful.

Although displacement by hydropower can be significant and must of course be well handled, the reader must keep in mind that other electrical generating options can also cause significant resettlement: coal mining and processing and coal ash disposal, also displace communities. GHG-induced climate change may eventually cause massive population migrations, if sea levels rise substantially.

As with the other environmental effects, social effects of hydro schemes are variable and project specific. A private developer must closely work with national and regional governments to provide for this aspect early in the planning stage of a project mobilizing sufficient resources and ensuring that the plan aligns directly with established national political and social policy. It is appropriate for the national and/or regional host government to lead and direct the required relocations. Whenever adverse impacts cannot be avoided or mitigated, compensation measures can be implemented.

A developer can often ensure that benefits are distributed, at least in the short term by utilizing local labor for the construction phase of a hydro scheme (which often lasts several years). Required access roads lead to easy influx of outside labor and the development of new economic activities, with resulting tensions if local and potentially resettled populations in the area are unprepared.

\subsubsection{A Sustainable Portfolio}

In conclusion, the environmental disbenefits, and benefits of hydro and the development of hydro around the world must be considered in the light of the sustainability of any given energy generation portfolio, whether the sample is restricted to an individual nation or is regional.

Some authorities have described four system conditions that allow us to test whether a generation portfolio meets the conditions for sustainability, at least with respect to its environmental dimension. The four system conditions are:

\section{Substances from the earth's crust must not systematically increase in nature}

Does a generating system including hydro meet this test? Yes. The greenhouse gas intensity of our system is substantially driven by fossil fuel generation. As an example BC Hydro, which is substantially hydro based, contributes only 42 tonnes CO2e/GWh (carbon dioxide equivalent per gigawatt hour) compared to the Canadian average of 230 and the US average of 610. As an example outside of the North America, it is reported that fossil-fuel generation, in China, contributed 23 million tons of $\mathrm{SO} 2$ in 
1995, causing 40 per cent of the total land area to be seriously affected by acid rain. The resulting damage to crops, forests, materials and human health was calculated, in 1995, to be more than US\$ 13 billion.

In North America the consumption of coal is at approximately the same level, though with somewhat more advanced emission "scrubbing".

\section{Substances produced by society must not systematically increase in nature}

Does a hydro's generating system meet this test? Yes -again using the example of BC Hydro, the only significant pollutants other than $\mathrm{CO} 2$ from the $\mathrm{BC}$ Hydro generation system is nitrogen oxides (NOx). Efforts are ongoing to substantially reduce NOx emissions using with selective catalytic reduction technology.

\section{The physical basis for the productivity and diversity of nature must not systematically be diminished}

Does Hydro generation meet this test? Yes- although undoubtedly, reservoirs have diminished productivity and diversity to some extent. Properly organized mitigation programs that enhance habitat productivity and diversity using techniques like spawning channels and minimum flows go a long way to keeping impacts within tolerable bounds.

\section{Fair and efficient in meeting basic human rights}

Does hydro generation system meet this test? It is difficult to say in general. To pass this test, the principles discussed above with respect to relocation, etc. must be addressed. Hydro generation clearly provides long term affordable energy to meet economic and lifestyle objectives, and with appropriate attention to the societal effects by responsible governments can be minimized.

\subsection{Project Development}

Although hydropower perfectly fulfils the requirements of sustainable development and is a major tool to reduce global warming, the technically feasible global potential is very little used at present (see Section. 2.2). Hydropower development is mainly hindered by the high and long-term investments required and by the fact that potential hydropower sites are often located at great distances from the dense consumer areas. Furthermore, large projects, especially these with large reservoirs, invoke severe discussions concerning their environmental impacts.

The strategies to overcome these disadvantages in the competition market in energy sectors are as follows:

- Privatization of the energy market and innovative financing of hydropower projects for example on the basis of BOO (Build-Operate-Own) and BOT (BuildOperate-Transfer) models. 
- Developing hydraulic schemes as multipurpose projects and splitting the costs.

- Development of revolutionary technologies based on superconductors for the transportation of electricity over long distances with insignificant loss.

- Taking into consideration of environmental and socio-economical issues from the very beginning of prefeasibility studies and involvement of ecologists as well as of all persons concerned by the project at its early stage of design.

\subsection{The Future}

This chapter has highlighted the three phases of the development of hydropower and has examined some of the opportunities to harness the untapped potential of the world.

Two facts are well understood by economists; first that of the world infrastructure stocks, the electricity sector needs to form a greater percentage (compared with for example roads and railways) and secondly that as a percentage of those infrastructure stocks, higher and middle income countries demonstrate nearly twice the value in the electricity sector than low income countries. A third aspect, highlighted in this chapter is the relative abundance of hydro potential in those countries in most need of power, and the final part of the equation is the fact that hydro is relatively benign to the climate compared to other generation.

The world has become increasingly aware of the overall damage being inflicted on the environment from a plethora of activities of mankind. Although hydro has drawbacks in terms of inundation, interruption of sedimentation, water quality etc., mankind has begun to understand that climate change and environmental degradation is a complex topic, perhaps - at present - too complex for any of us to fully understand, and perhaps hydro's advantages outweigh its disadvantages.

In the context of the scientific community's recognition that perhaps the main threat to biodiversity and food production is global climate change, the main issue appears to be to what degree will society accept some local impacts of hydropower, in order to mitigate the global impacts of climate change and other environmental threats from thermal pollution. In short we cannot afford to dismiss any form of renewable energy from the supply, and power generation solutions must be found that have the minimal impact on the climate.

Unfortunately in this period when there should be a beneficial acceleration of hydro development, the retreat of the major international agencies - such as the World Bank - from participation in major hydro development, in no small part because of the eloquence of the environmental community, has created a hiatus in the flow of funding of development, at least that funding based in the West.

Meanwhile the demand for increased power generation continues to climb, particularly in those regions of the world striving to "catch up" with the standard of living of the West. 
There are only four main forms of finance available for the construction of hydropower:

- Reinvested capital from existing utilities (both private and public)

- Host nation government capital

- Multilateral agency capital

- Private finance both from within the host country and from without.

There are challenges in attracting capital from these four sources to hydro that affect all of them to one extent or another:

1 Significant investment is required for rehabilitation of existing facilities and for "catch up" maintenance

2 The necessity of investing almost $100 \%$ of the capital before any return (compared to "pay as you go" for fossil fuel)

3 Uneconomic and unbalanced tariff structures, rendering the whole power sector financially unstable

4 Lack of creditworthiness in customers whether they are government institutions, industry or private purchasers

5 Significant associated infrastructure development needs such as access roads and transmission.

6 Small markets

7 The necessary addressing of environmental issues, often aggravated by external groups.

In the developing nations that have the greatest hydro potential, reinvested capital from the existing utilities and capital from the host nation government are often not available. Governments encouraging development have huge demands for capital from all sectors of infrastructure both for new works and for rehabilitation. The lack of such capital has been a key problem for development and often responsible for the challenges facing the power generation industry, and many governments have realized that public sector funds are simply inadequate concluding that the payment burden needs to be shifted as far as possible from taxpayer to user. But constraints to private sector investment are many and progress on regulatory, restructuring and privatization reform has yet to bring the dividends that are needed

As discussed the private sector has been invited to invest in hydro in the developing world but there are significant difficulties for private financing. It is well known that hydro engineering has reached a level of sophistication and maturity such that, given previous experience in the development of hydro, most technical difficulties of hydro implementation are well understood and can be solved (at a price). The main difficulties pertain to accurately forecasting and quantifying the risks and associated costs of each individual project. Numerous different factors control whether and to what extent private funding is available for a development in this "Phase III' of hydropower project development throughout the world. 
One of the difficulties with attracting private investment and finance to hydropower projects is the need for a higher return on equity than was traditionally sought by utilities and the multi lateral agencies. This has led to a system where heavy debt leveraging is essential. The large size of power sector investments and the shorter-term outlook of private investors also affect the nature of the projects that can be undertaken in the private sector. With the necessity of attracting private finance, controlling factors in development of power generation, and particularly of hydro are: (i) the scale of the capital investment, (ii) possibility for an attractive return on equity and minimum feasible debt service characteristics, (iii) security of project revenue during debt service, and (iv) management of the major project risk factors.

Table 2.8 indicates the principal risks associated with a hydro development.

\begin{tabular}{|l|l|}
\hline Political/Economic & Government Rules and Regulations \\
\hline & Inflation \\
\hline & Tax rate Variations \\
\hline Commercial & Economic Force Majeure \\
\hline & Demand \\
\hline & Power Purchaser Credit \\
\hline & Power Purchaser Longevity \\
\hline & Interest \\
\hline Currency & Refinancing \\
\hline & Capital and Credit Availability \\
\hline Technical (Geology and & Exchange Rates \\
\hline Hydrology) & Repatriation \\
\hline Environmental & \\
\hline & Inundation and Loss of Land Base \\
\hline & $\begin{array}{l}\text { Impacts on terrestrial and aquatic } \\
\text { Species }\end{array}$ \\
\hline Social & Approvals procedures \\
\hline & Resettlement \\
\hline & Public Attitudes to development \\
\hline Return on Investment & Project Area impacts and compensation \\
\hline Construction Time & \\
\hline
\end{tabular}

Table 2.8. Hydro Development Risks

All the difficulties must be addressed in order for private capital to be mobilized more fully, and to more efficiently use the available government and multi lateral finance. Assistance is needed from the international funding community if progress is to be made.

At the most basic level, hydropower participates in a worldwide intense competition for capital. The capital market does not give "preference" to infrastructure and power development as the World Bank and other multilateral and bilateral agencies have been doing. 
In fact power development, and particularly hydro is at a significant disadvantage compared to many other investments. Hydro projects of necessity often require a relatively long period of negative cash flow before any return can be realized, and investors must somehow be tempted to invest preferentially in hydro instead of (for example) factories producing domestic and export goods readily marketable and profitable in western countries.

Accordingly, the nature of the hydro projects to be undertaken in the private sector will be different from the mega projects previously considered by the major national utility companies. A review of the risks inherent in development can lead to an understanding of the projects more likely to be attractive to investors

The multilateral agencies have in the last ten years been less enthusiastic in funding hydro power, often as a result of the organized onslaught of criticism from opposition groups, which have at times protested directly to potential contractors and suppliers associated in providing implementation expertise.

The following characteristics are apparent in projects that have been demonstrated to be "bankable", or considered desirable by private investment:

- High Head - so that minimal amounts of water are needed, and Pelton wheels (i.e. simple and easily maintained equipment) can be used. High head also tends to require less reservoir area, which can reduce environmental impacts and approvals procedures

- Run of River - so that diversion structures are small and storage is minimized, again keeping costs low and reducing the environmental impacts associated with large reservoirs

- Surface Based Configuration - to minimize the construction and geological risks attendant to tunnels and underground powerhouse caverns

- Compact - so that the smallest stretch of river is affected

- Appropriate Size - to minimize exposure to potential future slowdown in the regional electricity demand

- Short development cycle and debt repayment.

Developers are no longer exclusively engineers and thus have had less exposure to the technical aspects of development. In the contemporary scenario developers are often financial experts with a focus on minimizing or avoiding risk that will look to a power project merely as a business investment that can be evaluated on the same basis as any other competing investment in other sectors of the economy. Such investors do not have an inherent technical connection with the industry other than its opportunity to meet attractive investment conditions. Therefore the typical developer will be seeking to offset risk, and place it with appropriate parties (who can manage it) along with meeting investment objectives.

A developer will be fully prepared to pay for offsetting risk, on condition of course that those placement costs can ultimately be recouped. As a result, development philosophy and practice are currently directed toward the Engineer/Procure/Construct (EPC) form of contracting in which much of the construction and design risk is placed on the contractor 
who is assumed to be more capable of managing this risk. It is also notable that the contractor would be much more familiar with these risks than would be the investors who often do not have long connections to the power or construction industry.

In general the ideal placement of commercial risk would be with the power purchaser (or the market) while the political risk is managed by selecting investment locations meeting minimum acceptable conditions. The remaining political risk may be mitigated by purchasing some cover through insurers or from multilateral agencies such as World Bank, Asian Development Bank, and other institutions.

Political and other market risks do typically decline as a host economy maintains its development. It is, therefore, not surprising that the power generation sector is moving forward more vigorously (in general) in those countries that have the potential to raise significant or all the required debt in their own financial markets. In other cases, as noted, the multilateral agencies have an important function that they are increasingly exercising in accepting the political risks attendant to a particular development proposal.

The scale of projects that may be expected to be developed by private financing in a particular locale or country is a subject of some interest. Given the list of desirables characteristics described earlier, and developer's orientation toward limiting their risk exposure, it is not surprising that in general hydropower project developments in Asia have been and can be expected to continue to be of limited size. Apart from one or two notable exceptions, privately funded development to date tends to be less than about $180 \mathrm{MW}$. Few privately funded projects larger than $250 \mathrm{MW}$ are anticipated in the foreseeable future other than under very special conditions where the national government may take a direct role in risk management in partnership with the developer.

As economies become more developed, as power prices more fully reflect real investment costs, and as the equity and reinsurance markets develop further, gradually larger projects may be expected. However, it is worth noting that some of the geo-technical and cash flow difficulties and risks that are attendant on hydro projects are less important for thermal projects. Unless there are other constraints on thermal development, such as those related to international agreements on global warming, thermal project proposals will continue to be regarded by private developers as more viable than hydro and will take precedence.

What have been termed "mega Projects" (an arbitrary definition might be those above 1000 MW) clearly are not favored under the present scenario for private development, and will for the moment remain outside of the pattern. Projects of this scope and size encompass extraordinary market risk, often have significant geotechnical and construction risk, and of course may become a lightning rod for enhanced political risk. However, as shown by the example at Bakun, in many cases a mega project private development proposal is unlikely to succeed in the absence of extraordinary support from the government and special power purchase and contractual terms.

In the meantime, in the absence of funding from the international agencies and the difficulties of attracting private finance, a powerful force has appeared that may facilitate 
rescue of major hydro development. The Chinese government through numerous agencies such as the China Exim Bank and quasi government organizations such as Sinohydro, and the Three Gorges Corporation, are supporting many projects particularly in Asia and Africa, by financing, and constructing the projects.

As the other countries and international organizations shy away from hydropower development assistance Chinese companies and banks are now involved in billions of dollars worth of contracts and memos of understanding to construct nearly 50 major projects in 27 countries. It has been reported that officially China does not attach "strings" to its loans and grants.

In Southeast Asia alone, some 21 Chinese companies are involved in 52 hydropower projects of various sizes, according to research issued this year at the China-ASEAN Power Cooperation \& Development Forum.

There will eventually be an end to China's largesse, and in order to mobilize finance from the greater international community, it is imperative to make the environmental process more predictable. Not only that, but the market must give clear price signals to the financial community that the development of resources that have low emissions present less risk and greater reward. Renewable Energy credits and carbon offsets can also help. In the various markets in which Hydro plays a part some or all of the following challenges need to be addressed:

- Clear Energy Policy (National, regional and global)

- Simplifying and streamlining regulatory requirements and approvals (the Decision Making Process)

- Furthering Public-Private Partnerships

- Transparent and equitable regulation

- Fully, but efficiently, engage stakeholders (including benefit sharing)

- Provide fiscal incentives (tax holidays, tax credits, green credit (carbon offset) programs)

- Market signals favoring low emissions (consistent signals for sustainable development)

- Strengthening of local financial markets to allow for minimization of exchange rate risks

- Transmission infrastructure investment

- Significant investment for rehabilitation and catch up maintenance

- Reform of uneconomic and unbalanced tariff structures, which render electricity markets financially unstable.

Attending to these aspects, cumulatively and with the global pricing signals, could form the basis of guidelines for the development and management of hydropower projects and constitute a sustainable approach to renewable hydropower resource development.

A significant number of developed countries now have legislation, regulations and incentive packages to encourage the development of various renewable generation within 
their own countries - perhaps now is the time to enhance the conditions for overseas development assistance for renewables and medium to large scale hydro by similar practices encouraging cross border hydro investment in developing nations.

As part of the restructuring of the energy markets, the creation of a spot market sometimes occurs, but spot markets in energy are too volatile to signal investment in hydro with perhaps the special case of pumped hydro which can take advantage of high differential prices during the day.

Hydroelectric power has an important role to play in the future, and provides considerable benefits to an integrated electric system. The worlds remaining hydroelectric potential needs to be considered in the new energy mix, with planned projects taking into consideration social and environmental impacts, so that necessary mitigation and compensation measures can be taken. Clearly, the population affected by a project should enjoy a better quality of life as a result of the project.

Any development involves change and some degree of compromise, and it is a question of assessing benefits and impacts at an early enough stage, and in adequate detail, with the full involvement of those people affected, so that the right balance can be achieved.

Two billion people in developing countries have no reliable electricity supply, and especially in these countries for the foreseeable future, hydropower offers a renewable energy source on a realistic scale.

\subsection{Acknowledgement}

This Chapter has been prepared by Brian Sadden, Consulting Civil Engineer, Montgomery Watson, Harza, USA.with contributions by David. A. Balser (Manager Environmental Group, BC Hydro, Canada), Olcay Unver (Regional Development, Southern Anatolia Project, Turkey), the late Jan Veltrop (Commissioner, World Commission on Dams, USA), Yang Haitao and Yao Guocan (EPRI, Beijing, China), Brian Gemmell (Marketing Manager (North America), ALSTOM Power Electronic Systems, New York, USA), John Loughran (GEC, Stafford, UK), and Hilmi Turanil (Manitoba Hydro, Canada).

\subsection{References}

[1] Renewables 2007 - a global status report by Renewable Energy Policy Network for the 21st Century.

[2] Boletim Energia No 206, published by ANEEL, February 2006

[3] Powering China's Development: The Role of Renewable Energy, Eric Martinot, Li Junfeng, November 2007[4. World Atlas and Industry Guide published annually by the International Journal on Hydropower and Dams

[5] International Water Power \& Dam Construction Yearbook (1997)

[6] ICOLD 1998

[7] International Energy Authority

[8] United Nations "Energy Statistics Yearbook, United Nations, 1995 


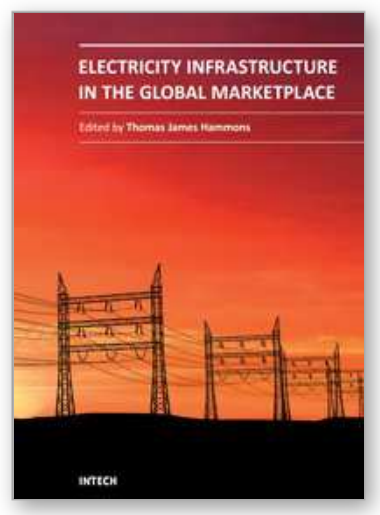

\author{
Electricity Infrastructures in the Global Marketplace \\ Edited by
}

ISBN 978-953-307-155-8

Hard cover, 802 pages

Publisher InTech

Published online 27, June, 2011

Published in print edition June, 2011

This book discusses trends in the energy industries of emerging economies in all continents. It provides the forum for dissemination and exchange of scientific and engineering information on the theoretical generic and applied areas of scientific and engineering knowledge relating to electrical power infrastructure in the global marketplace. It is a timely reference to modern deregulated energy infrastructure: challenges of restructuring electricity markets in emerging economies. The topics deal with nuclear and hydropower worldwide; biomass; energy potential of the oceans; geothermal energy; reliability; wind power; integrating renewable and dispersed electricity into the grid; electricity markets in Africa, Asia, China, Europe, India, Russia, and in South America. In addition the merits of GHG programs and markets on the electrical power industry, market mechanisms and supply adequacy in hydro-dominated countries in Latin America, energy issues under deregulated environments (including insurance issues) and the African Union and new partnerships for Africa's development is considered.

Thomas James Hammons (Fellow IEEE 1996) received the B.Sc. degree in Engineering (1st Class Honors), and the DIC, and Ph.D. degrees from Imperial College, London, UK He is a member of the teaching faculty of the School of Engineering, University of Glasgow, Scotland, UK. He was Professor of Electrical and Computer Engineering at McMaster University, Hamilton, Ontario, Canada in 1978-1979. He is the author/co-author of over 440 scientific articles and papers on electrical power engineering and is Editor of a book on Renewable Energy that was published by INTECH in December 2009. He has lectured extensively in North America, Africa, Asia, and both in Eastern and Western Europe.

Dr Hammons is Past Chair of the United Kingdom and Republic of Ireland (UKRI) Section IEEE and Past Chair of International Practices for Energy Development and Power Generation of IEEE. He is also a Past Chair of the IEEE PES Task Force on harmonizing power-engineering standards worldwide and Past Permanent Secretary of the International Universities Power Engineering Conference. He is a Chartered Engineer (CEng) and a registered European Engineer in the Federation of National Engineering Associations in Europe.

\title{
How to reference
}

In order to correctly reference this scholarly work, feel free to copy and paste the following:

T. J. Hammons (2011). Harnessing Untapped Hydropower, Electricity Infrastructures in the Global Marketplace, (Ed.), ISBN: 978-953-307-155-8, InTech, Available from:

http://www.intechopen.com/books/electricity-infrastructures-in-the-global-marketplace/harnessing-untapped-

hydropower 
open science / open minds

InTech Europe

University Campus STeP Ri

Slavka Krautzeka 83/A

51000 Rijeka, Croatia

Phone: +385 (51) 770447

Fax: +385 (51) 686166

www.intechopen.com
InTech China

Unit 405, Office Block, Hotel Equatorial Shanghai

No.65, Yan An Road (West), Shanghai, 200040, China

中国上海市延安西路65号上海国际贵都大饭店办公楼 405 单元

Phone: +86-21-62489820

Fax: +86-21-62489821 
(C) 2011 The Author(s). Licensee IntechOpen. This chapter is distributed under the terms of the Creative Commons Attribution-NonCommercialShareAlike-3.0 License, which permits use, distribution and reproduction for non-commercial purposes, provided the original is properly cited and derivative works building on this content are distributed under the same license. 